\title{
Systematic and data-driven literature review of the energy and indoor environmental performance of swimming facilities
}

\author{
Ole Øiene Smedegård (D) Bjørn Aas · Jørn Stene • \\ Laurent Georges $\cdot$ Salvatore Carlucci
}

Received: 20 January 2021 / Accepted: 14 August 2021/ Published online: 18 September 2021

(C) The Author(s) 2021

\begin{abstract}
During the last few decades, focus on measures for energy conservation in buildings has increased considerably. The European Commission implemented the Energy Performance of Buildings Directive, which gave instructions to the member states about how to reduce energy consumption
\end{abstract}

\section{Highlights}

- A total of 524 scientific papers on heating, ventilation, and air conditioning in swimming facilities are identified, selected, and reviewed.

- Bibliometric and thematic analyses are performed for the selected 524 papers.

- Swimming facilities are complex buildings which require numerous interacting disciplines.

- The research field of disinfection by-products in swimming facilities appears to be mature.

- The coverage of energy and indoor environmental quality in swimming pools is, so far, fragmented and noncomprehensive.

- Research is required to bridge the entire knowledge chain from the physico-chemical reactions in the pool water to the overall facility energy consumption.

O. Ø. Smedegård · S. Carlucci

Department of Civil and Environmental Engineering, NTNU Norwegian University of Science and Technology, Trondheim, Norway

O. Ø. Smedegård · J. Stene

COWI AS, Trondheim, Norway

O. Ø. Smedegård $(\bowtie) \cdot$ B. Aas $\cdot$ S. Carlucci Department for Civil and Transport Engineering, SIAT NTNU-Centre for Sport Facilities and Technology, Norwegian University of Science and Technology, in residential and non-residential buildings. In the process of making the building sector more energy efficient, the building codes generally have become stricter with some simplifications applied in the requirements. For swimming facilities in Norway, these simplifications are undermining the purpose of the code by excluding the energy use related to the operation of swimming pools, which is the main part of the energy use in this building category. In other words, the energy use related to operation of the facility is not regulated. Furthermore, guidelines for the planning and operation of these types of facilities are outdated and research for this building category is sparse. These three aspects mean that there is a considerable potential for improvement. This paper presents a comprehensive literature review with bibliometric and thematic analyses of the contextualized research in swimming facilities from a heating, ventilation, and air-conditioning perspective. It maps the

\author{
Trondheim, Norway \\ e-mail: ole.smedegard@ntnu.no \\ J. Stene $\cdot$ L. Georges \\ Department of Energy and Process Engineering, NTNU \\ Norwegian University of Science and Technology, \\ Trondheim, Norway \\ S. Carlucci \\ Energy, Environment and Water Research Center, The \\ Cyprus Institute, Nicosia, Cyprus
}


major trends during the past few decades, where areas like solar heating for outdoor pools, energy consumption, and air quality stand out. Except for air quality and disinfection by-products, research on these facilities is highly fragmented without any strong contributors to the various fields.

Keywords Swimming facilities $\cdot$ HVAC $\cdot$ Energy · Indoor environmental quality $\cdot$ Disinfection by-products

\section{Introduction}

\section{Background}

The global climate change has been disclosed over the past 30 years and has been periodically stated by the Intergovernmental Panel on Climate Change (IPCC), since their first report in 1990 (Tegart et al., 1990). As a consequence and after the establishment of the Kyoto protocol in 1997, the European Union implemented the Energy Performance of Buildings Directive, EPBD (European Commission, 2006). EPBD was partly designed to meet the $20 \%$ indicative target for energy efficiency improvement defined by the EU Energy and Climate Package.

Within the European Commission's vision of climate neutrality by 2050 (European Commission, $2019 \mathrm{~b}$ ) and the proposed raising of the greenhouse gas reduction target to at least 50\% toward 2030 (European Commission, 2019a), a "renovation wave" of the building sector has been defined in the related action plan. For the specific case of swimming facilities, research has revealed a large span in energy use for the buildings. Their specific energy use, expressed as delivered energy per square meter and annum, has been reported to range from $400 \mathrm{kWh} /$ $\left(\mathrm{m}^{2}\right.$.a) to almost $1600 \mathrm{kWh} /\left(\mathrm{m}^{2}\right.$.a) (Kampel et al., 2013; Kampel, 2015; Røkenes, 2011; Swim England, 2016). Kampel (2015) investigated the energy use of Norwegian swimming facilities and found its range to be wide even if it was normalized to different variables, like number of visitors or pool's water surface. This variation can partially be explained by the variety of subcategories within swimming facilities, the age of the building, the difference in installed technology, and the maintenance routines. This all represents a large energy savings potential (Kampel,
2015). Considering that modern office and residential buildings are characterized by a specific delivered energy use below $100 \mathrm{kWh} /\left(\mathrm{m}^{2}\right.$.a), swimming facilities represent an energy-intensive building category. Consequently, in the context of the EU Roadmap 2050 (European Commission, 2019b), it is a paradox that swimming facilities are not treated exclusively, rather just included as a sub-category of "sport facilities," which are characterized by totally different size, uses, period of operation, and, of course, energy consumption (European Union, 2010).

\section{Motivation}

Due to the range in energy use, Kampel et al. (2013) called for increased research activity regarding the development of representative Final Annual Energy Consumption (FAEC) indices. Duverge et al. (2017) pointed to the complex nature of swimming facilities as a reason for the lack of research and standards related to this kind of facility. The research field regarding energy performance and water usage is suffering from the lack of worldwide research activity (Duverge et al., 2018). However, research and design in swimming facilities require a high level of holistic knowledge due to the multiple and inherently connected subjects, like indoor environmental quality, chemo-physical reactions in both water and air, water treatment and management, technical building systems for environmental control, and energy efficiency, among others. The complexity of these facilities is also reflected by the number and typologies of the technical systems required in a typical swimming pool. Figure 1 shows a general illustration of the typical circular dependencies in swimming facilities found in Scandinavian conditions (i.e., zone D according to the climate zones definition of Köppen \& Geiger, 1930).

Referring to Fig. 1:

1. The indoor environment (1) is normally controlled by fixed set-points for indoor (dry-bulb) air temperature and relative humidity. The ventilation system is dedicated to handle all issues related to the indoor environmental quality and provide a healthy and thermally comfortable indoor environment. The air distribution is typically also designed to eliminate condensation 


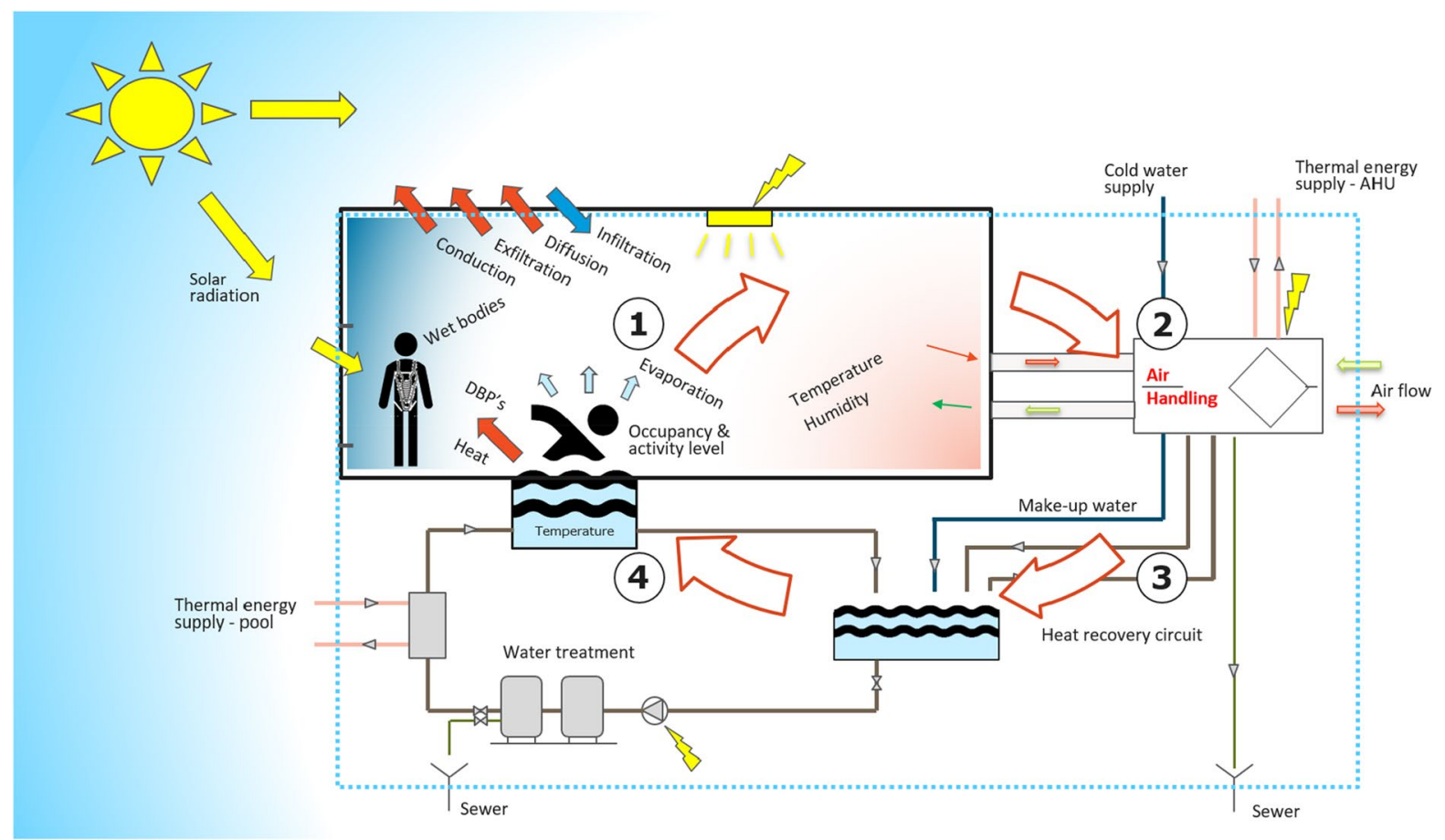

Fig. 1 Schematic operation concept of a swimming facility within Scandinavian conditions with key elements related to space and water heating, ventilation, air conditioning and dehumidification, and water treatment; (1) indoor environment,

problems on the facility envelope and structural systems.

2. The evaporation rate for pools greatly depends on the occupancy and activity levels. The air handling unit (AHU, 2) controls the humidity and air temperature in the pool hall by heating and varying the state of the supplied air. Depending on the operation mode, bathing or night mode, the AHU recovers the latent heat from the extracted air, normally with an integrated heat pump. In night mode, most of the air flow is recirculated into the hall, with the purpose of maintaining the room temperature and humidity set-points in reasonable ranges. Since the energy level in the supply air flow depends on the thermal losses of the pool hall, and the energy level in the extract air depends on the evaporation from the pool surface, the direction of the net energy flow may vary in operation. However, the net energy flow related to the ventilation system in modern swimming facilities, with high energy performance, will normally be negative, as illustrated in Fig. 1.
(2) air handling, (3) heat recovery circuits, and (4) water treatment system, where the arrows illustrate the typical direction of the net energy flow

3. The heat recovery circuit (3) is connected to the AHU and the recovered latent heat is used for either air or water heating. This represents a crucial link in the energy loop of the facility.

4. If required, additional thermal energy and water refill are supplied in the water treatment system (4). This loop circulates the water through the pool where the water quality is strictly monitored and controlled, along with its temperature.

The relationship between the different key elements in the swimming facility illustrates the vulnerability of the system and the risk of both excessive energy use and an improper and possibly harmful indoor environment. For example, the performance of the AHU influences the indoor environment and the energy use as it controls the indoor environment and recovers latent heat from the extracted air. The performance of the AHU also influences the energy use for the pool circuit due to the heat recovery system and the control of the water temperature in the pool. 
The performance of the pool circuit influences the indoor environment by the water quality, filtering, disinfection and disinfection by-products, and thereby the air quality, but also by the temperature control, which is crucial for controlling the evaporation rate. The latter is greatly dependent on the water and air temperatures. A high evaporation rate increases the energy content in the pool air, which in turn will increase the ventilation losses. High humidity will also increase the risk of condensation on building envelope surfaces and make the pressure gradient steeper inside the pool hall. This may cause degradation of the construction due to corrosion and possible exhilaration and increased diffusion and possible accumulation of moisture inside envelope components.

The illustrated interconnections show the importance of understanding the varied and complex nature of swimming facilities when dealing with optimization or improvements. For example, the importance of in-depth knowledge regarding the AHU's control system is crucial when evaluating the air quality inside the hall since the fresh air supply flow rate typically fluctuates during operation and together with it the dilution of the contaminants in the hall. Another example is the consequences of the interconnected heat recovery and energy system. Even if the facility has satisfactory overall energy performance, multiple issues may be present. For example, issues related to the water refill system can disguise problems with the air handling unit and the fresh air supply.

Considering the lack of regulations related to the energy use in swimming facilities, it is beyond doubt that the different technical systems are very often sub-optimized.

\section{Purpose}

Within the field of swimming facilities, several literature reviews were carried out in the past decade. They include themes regarding prediction of the evaporation rate during natural convection (Poós \& Varju, 2019), disinfection by-products in swimming pools (Carter \& Joll, 2017; Chowdhury et al., 2014; Manasfi et al., 2017), and heating technologies for swimming pools ( $\mathrm{Li}$ et al., 2020). Motivated by the reported potential for energy optimization, and the need for research, regulations, and guidelines addressing the complexity of these facilities, this paper presents and discusses a systematic literature review of the energy and the indoor environmental performance of swimming facilities. It presents new knowledge, regarding the present contextualized research related to HVAC systems in swimming facilities, and depicts the scientific landscape, which is based on both bibliometric and thematic analyses. This work describes the state of the art regarding the multidisciplinary field of HVAC systems in swimming facilities in cold climate regions such as northern Europe.

\section{Methodology}

Swimming facilities represent a building type where research addresses either the technical aspects of the facility or the activities carried out in the facility (biomechanics, swimming techniques, statistical studies regarding drowning etc.). This literature review deals with the technical and engineering aspects of the facilities with a focus on those aspects related with the indoor environmental quality (IEQ) and heating, ventilation, and air conditioning (HVAC).

The literature review has been carried out following a three-step methodology illustrated in Fig. 2. The methodology uses a systematic and data-driven bibliometric analysis to collect and investigate data from publications available in the scientific literature. The outcome of each step is analyzed in "Methodology" section, where an analysis of the identified and collected publications is presented.

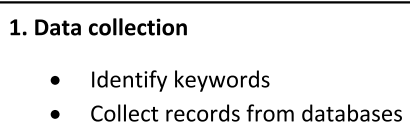

\section{Data filtering}

- Filter records based on type, language

- Remove duplicates

- Remove irrelevant records

\section{Data analysis}

- Apply the dataset to VoSviewer and Bibliometrix

- Perform bibliometric analysis

- Perform thematic analysis

Fig. 2 Holistic methodology workflow chart 
The data collection

The development of the search string, box no. 1 in Fig. 2, is based on the aim of the study, a mapping of the scientific landscape of publications with respect to the technical part of swimming facilities. This approach defines a broad system boundary which makes it possible to conduct an analysis of the facility-relevant research in this field. The technical areas of interest, defined from the field of HVAC and IEQ, include.

- Energy,

- Air quality,

- Ventilation,

- Disinfection by-products.

The following major databases were used in the analysis:

- Scopus,

- Web of Science (WoS),

- Compendex (Elsevier).

Figure 3 illustrates the workflow related to the establishment of the dataset of raw data, box no. 1 in Fig. 2 (Data collection).
The search string was applied to the databases and the bibliometric data were collected on February 23, 2020. The search was carried out by searching in title, keywords, and abstract (topics). The search resulted in a dataset of bibliographic data with 1993 records. The distribution of the records before filtering was approximately $50 \%$ Scopus, $25 \%$ Web of Science, and 25\% Compendex.

Filtering data

The filtering process was carried out in four steps:

1. Document type: limit the records to journal or conference articles,

2. Language: limit the records to documents written in English,

3. Duplicates: excluding duplicates in the dataset,

4. Relevance: excluding irrelevant records.

Figure 4 illustrates the impact of the individual filtering steps on the number of records, and the distribution.

Figure 4 reveals a distinct change in the distribution between the databases at filtering step 3, "Removing duplicates." This change is due to the prioritized order of removing objects. During this step, articles with origin from Compendex were removed
Fig. 3 Illustration of the process of establishing a raw dataset. * Refer to the truncation symbol in the search string. The truncation symbol allows you to search for all the various endings of a word

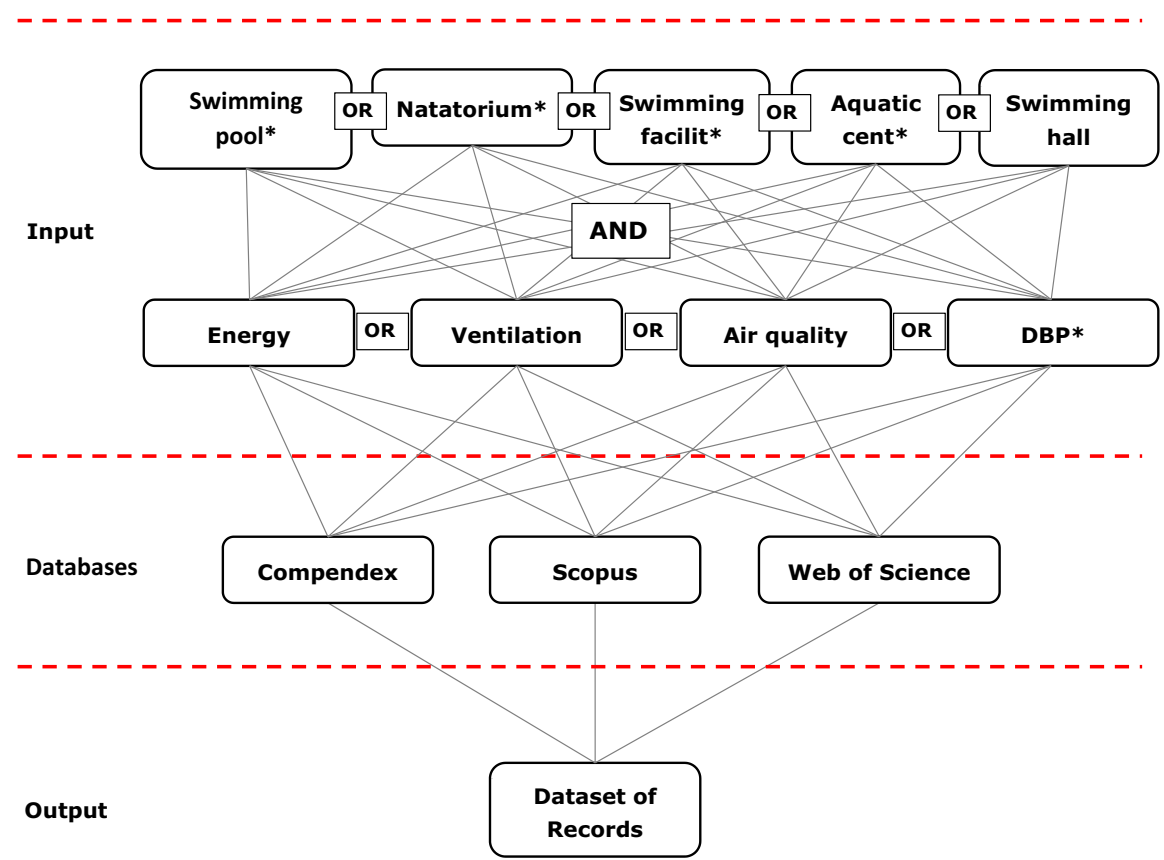


Fig. 4 The impact of the filtering steps on the original dataset

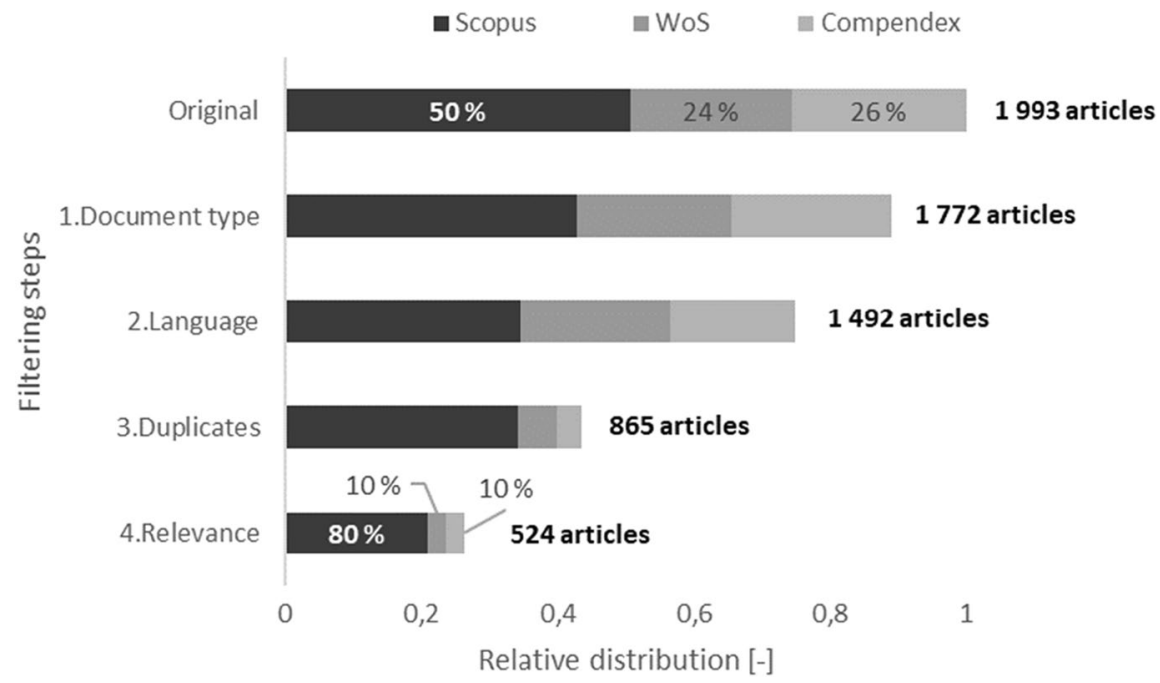

first, and second the records from Web of Science. The reason for this order was the lack of information which is provided in the bibliometric extraction by Compendex.

Regarding the last filtering step 4 "Relevance," the dataset was reduced by almost $40 \%$. This reduction was due to the broad search string. Irrelevant records were filtered out manually by screening the title and abstract. If the research presented outcomes, which were not in the scope of our study, they were excluded from the dataset and subsequent analyses.

Analyzing data

\section{Identification process}

Prior to the analyzing section, extensive identification was required. The facilities were mapped, and subsystems and key-areas were identified by a unique tag. By screening titles and abstracts for the dataset of 524 articles, a tag was assigned to each article. The aim of the tagging system, the structural map, was to further reduce the dataset to investigate the research within the field. Figure 5 illustrates the overall topography of the structural map used for tagging the articles.

In addition to the tag system previously described, the articles are categorized both by the type of facility and the approach of the study, deterministic or analytical. The type of facility has been identified by public or residential indoor and outdoor pools since these categories differ significantly in design, operation, and typical issues.

\section{The analysis}

The analysis has been divided into two parts: (1) bibliometric analysis and (2) thematic analysis. The bibliometric one provided information about the knowledge structure and development of the research field in the context of swimming facilities. This involved analysis of authors' productivity, affiliations, and publication year and publication countries (of their affiliated organizations) as well as co-occurrence of words in a text and the co-occurrence of the keywords listed under the abstract. The thematic analysis was based on a quantitative analysis of each of the publication's

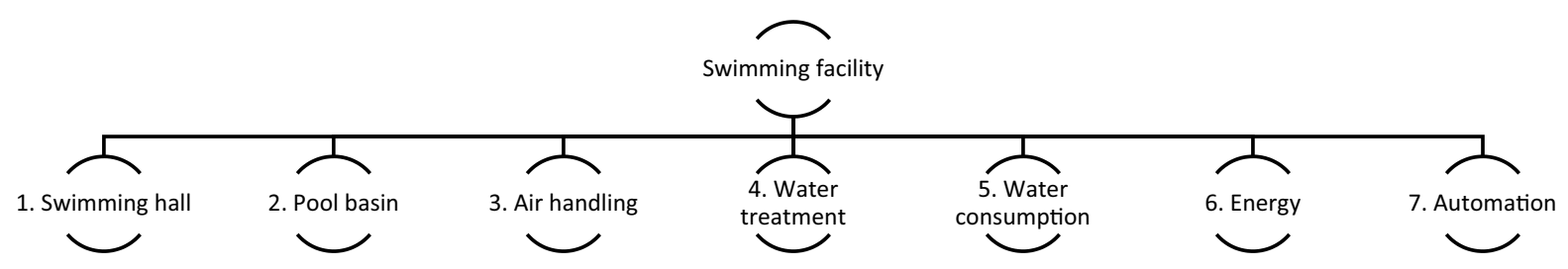

Fig. 5 The overall topography of the structural map. Each category was represented with several sub-categories 
finding. This was identified by full-text review of the publications and structuring/discussion in the context of the HVAC system.

The bibliometric analysis comprises 524 documents published between 1930 and 2019. The dataset is created according to Fig. 4, as the outcome of step 4 . The dataset has been investigated by the use of VOSviewer (van Eck \& Waltman, 2010) and Bibliometrix (Aria \& Cuccurullo, 2017), and the results are reported in several perspectives and subsections.

\section{Results of bibliometric analysis}

This section provides information about the knowledge structure and the scientific landscape of the respective research fields.

Publication trends and structural analysis

The dataset can be divided into public and residential swimming pools. Studies regarding residential swimming pools almost entirely comprise outdoor pools with energy-related focus in the dataset (Harrington \& Modera, 2013; Nouanegue et al., 2011; Ruiz \& Martínez, 2010; Song et al., 2018). This is also the case for public outdoor swimming pools, where about $80 \%$ of the studies deal with the energy system. The dominant topic within the energy subcategory is solar energy, represented by about $40 \%$ of the articles. This dominance is reasonable because solar energy has been an important heat source for open-air swimming pools for decades (Ruiz \& Martínez, 2010).

By arranging the dataset with respect to the year of publication, as illustrated in Fig. 6b, the interest in solar energy (regardless of the type of swimming facilities) is observed to be constant since the 1980s, with the exception of a drop during the first period in the new millennium. This in relation to the absolute publication rate, where the solar energy-related studies dominate the number of publications in the pre-millennial period. Figure 6 a illustrates the dataset divided into three main categories:

1. HVAC and engineering in public indoor facilities,

2. Disinfection by-product (DBP)-related studies,

3. Outdoor and public swimming pools.
The remaining part of the records, apart from the studies regarding outdoor and/or residential swimming facilities, represents $15 \%$ of the publications in the last two decades, as illustrated in Fig. 6a. These publications include DBPs, HVAC, and engineeringrelated topics, all technical, constructional, and operational. Figure 6a illustrates the distribution between the defined groups, where the last two are represented by approximately 40 and $45 \%$, respectively. Bearing in mind the importance of proper air quality and the toxicity of the DBPs, which have been linked to adverse health effects (Richardson et al., 2010), as well as the parallel worldwide focus on energy use and consequent environmental impact, this distribution is expected.

When looking into the publication trend, the publication rate versus the publication year, the strong increase of the DBP-related publications rate in the last decade is revealed. This increase can be seen for the whole dataset as well, where $75 \%$ of the articles are published after 2000. By comparison, looking exclusively at the DBP publications, $90 \%$ of the DBPrelated articles are published in the last 15 years.

Publication year and average publication year

In the last two decades, there are only 154 publications within the HVAC and engineering category. The average publication year is 2013 , which indicates an increasing number of publications toward this period. This pattern is illustrated in both Fig. $6 \mathrm{~b}$ and c. This offset of the average publication year for the last two decades makes this a state-of-the-art study. Figure $6 \mathrm{~b}$ Illustrates the distribution for the entire dataset which confirms this conclusion.

\section{Sources}

For the HVAC and engineering category, $85 \%$ of the publications in the last two decades can be found in the Scopus database. Approximately one third are conference papers and the dominating scientific journal source is "Energy and Buildings" with about $10 \%$ of the publications (Fig. 7). Only 5 out of 84 sources in this dataset have published more than 2 articles. This indicates a fragmented research field where no specific scientific journals, besides "Energy and Buildings," emphasize contextualized research about swimming facilities. 
Fig. 6 The structural overview of publications with respect to a main topics; $\mathbf{b}$ publication timeframes; $\mathbf{c}$ research topics (a)

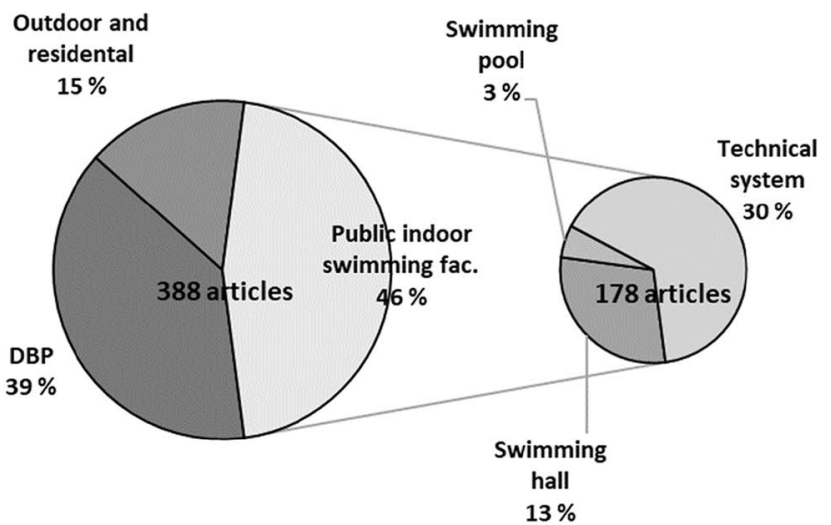

(b)

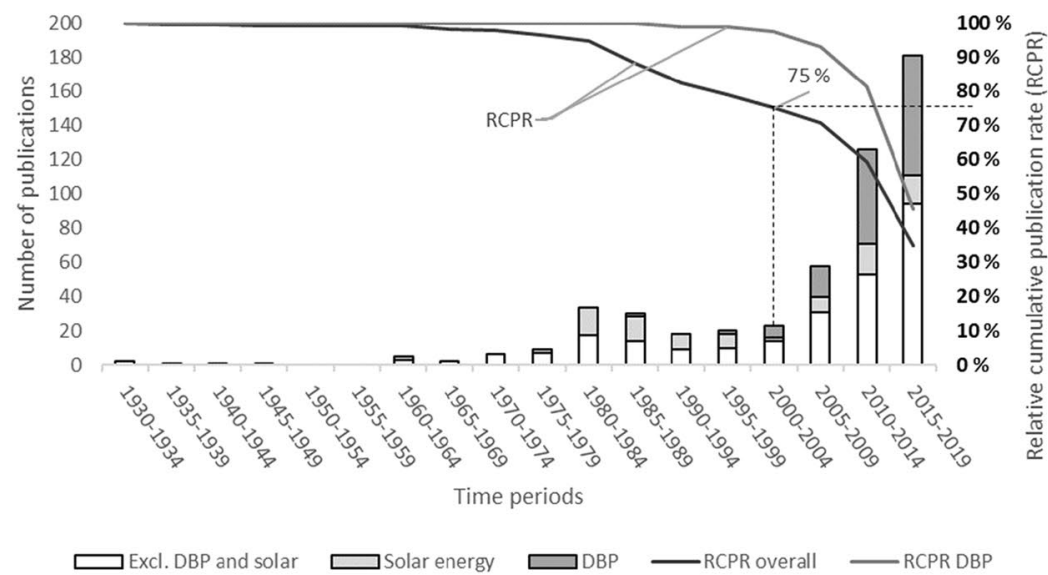

(c)

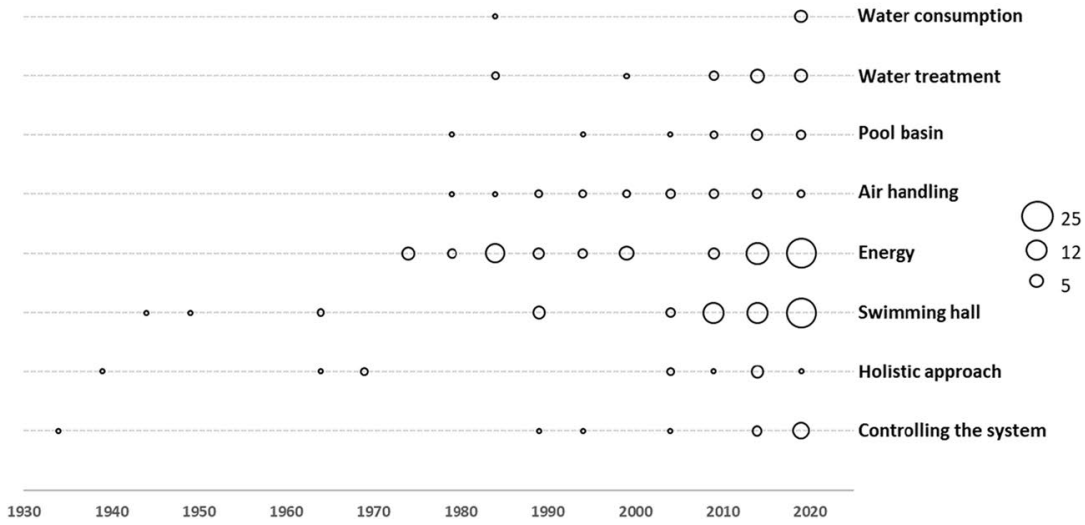

Authors and institutions

Research in the context of swimming facilities is a field of growing interest. The publication rate has been constantly increasing over the last two decades, cf. Figure 6b. For the bibliometric dataset of Scopus records related to the HVAC and engineering category, a total of 290 authors are represented. The distribution of the authors' publication rate depicts a field identified by many occasional authors where approximately $90 \%$ have only one publication. The pattern of a fragmented field can also be seen in the 
Fig. 7 Most relevant sources with number of published articles

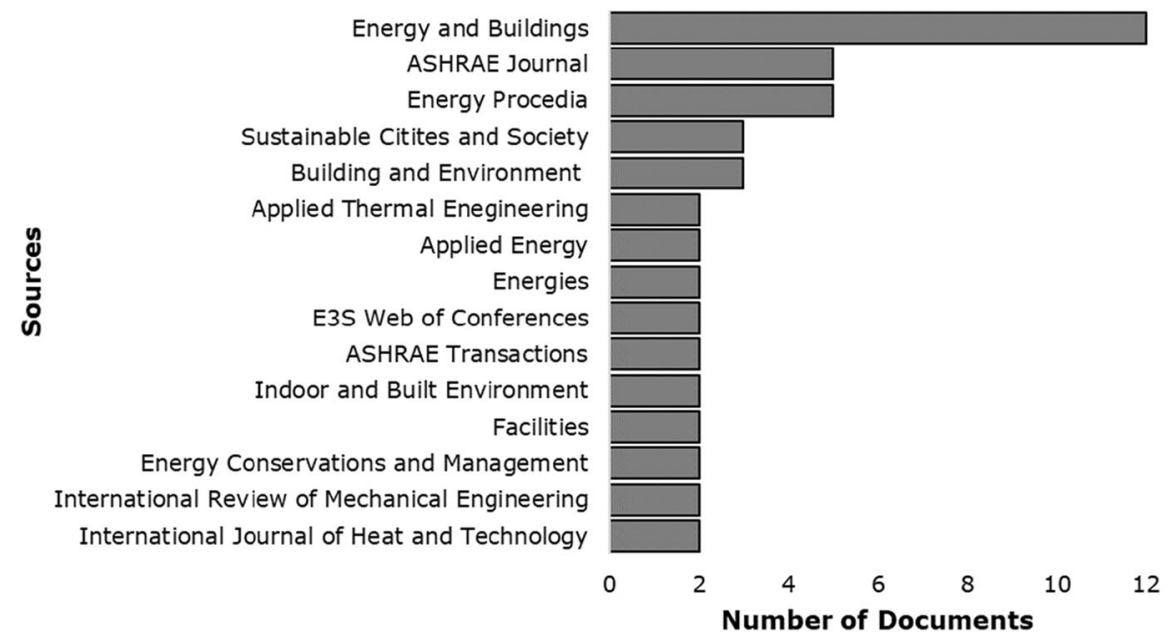

distribution of authors as well. A comparison with Lotka's law, which describes the publication frequency by the authors, demonstrates that the respective field is identified by few authors with multiple publications. Lotka's law is one of the basic laws of informetric and explains the distribution of the scientific productivity within a field. It shows that the relation between the number of authors publishing a certain number of articles is a fixed ratio to the number of authors publishing one article. The relation is approximately inverse square.

Parallel to this, the group of core authors is equivalently small, where only five authors are represented by three publications. This wide dispersion is scrutinized in Fig. 8b, which depicts the total amount of publications for the whole pool of authors $(n=290)$. The overall picture of this distribution is the occasional pattern. Rajagopalan from Australia is by far the most contributing author and, along with Bruland's group at the Norwegian University of Science and Technology (NTNU), represents the core group of authors. Both Rajagopalan's and Bruland's groups have publications with a comprehensive approach, each with $\mathrm{PhD}$ theses within the subject (Duverge, 2019; Kampel, 2015). Both research groups focus on the energy use in swimming facilities.

\section{Contributing countries}

The popularity and significance of a research field can be identified by tracing the span of the geographical area and the contributing countries. The dataset of the HVAC and engineering research area for the last two decades represents 154 articles. By rearranging these with respect to the corresponding author, this contextualized research is of special interest in the developed countries. Europe is the main contributor by 76 articles and North America second by 34 articles, together representing over $70 \%$ of the publications. Figure 9 illustrates the distribution over the continents. The publication intensity is well distributed in Europe, where 19 countries have contributed with publications. Portugal and Italy are the most contributing countries, each with nine articles followed by Germany and UK with seven publications each (Fig. 10). This depicts a research area with good bibliometric dispersion.

Key areas

Even though the published articles in this predefined field apparently seem fragmented, the pool of records is closely connected in the thematic perspective. This is illustrated in a Sankey diagram (Riehmann et al., 2005) organized as a three-field plot in Fig. 11 (Aria $\&$ Cuccurullo, 2017). This plot shows the most frequent words in abstracts, author's keywords, and sources (scientific journals), illustrated by the size of the boxes. The strength of the connections is identified by the line between the boxes. The most frequent words identified in the abstracts give the main terms of the research questions while the field of the author's keywords gives the main concepts on which the domain is built (Carlucci et al., 2020). The terms "energy efficiency," "heat pump," and "indoor air quality" stand out in the abstracts, besides the obvious 
Fig. 8 The distribution of the authors publication rate in the Scopus dataset (a)

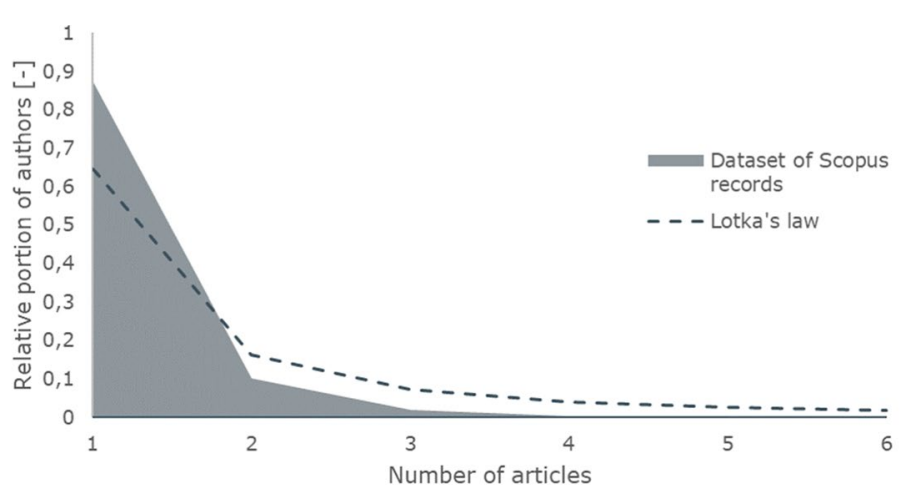

(b)

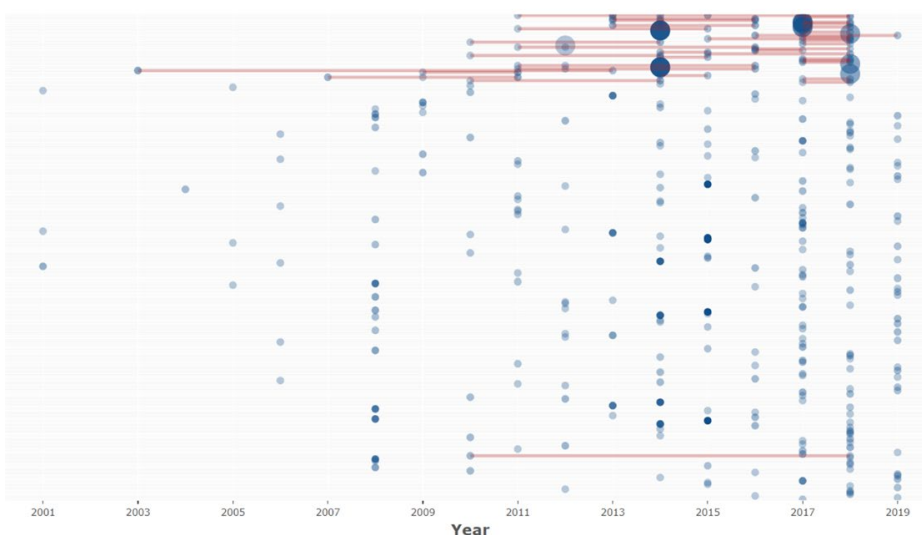

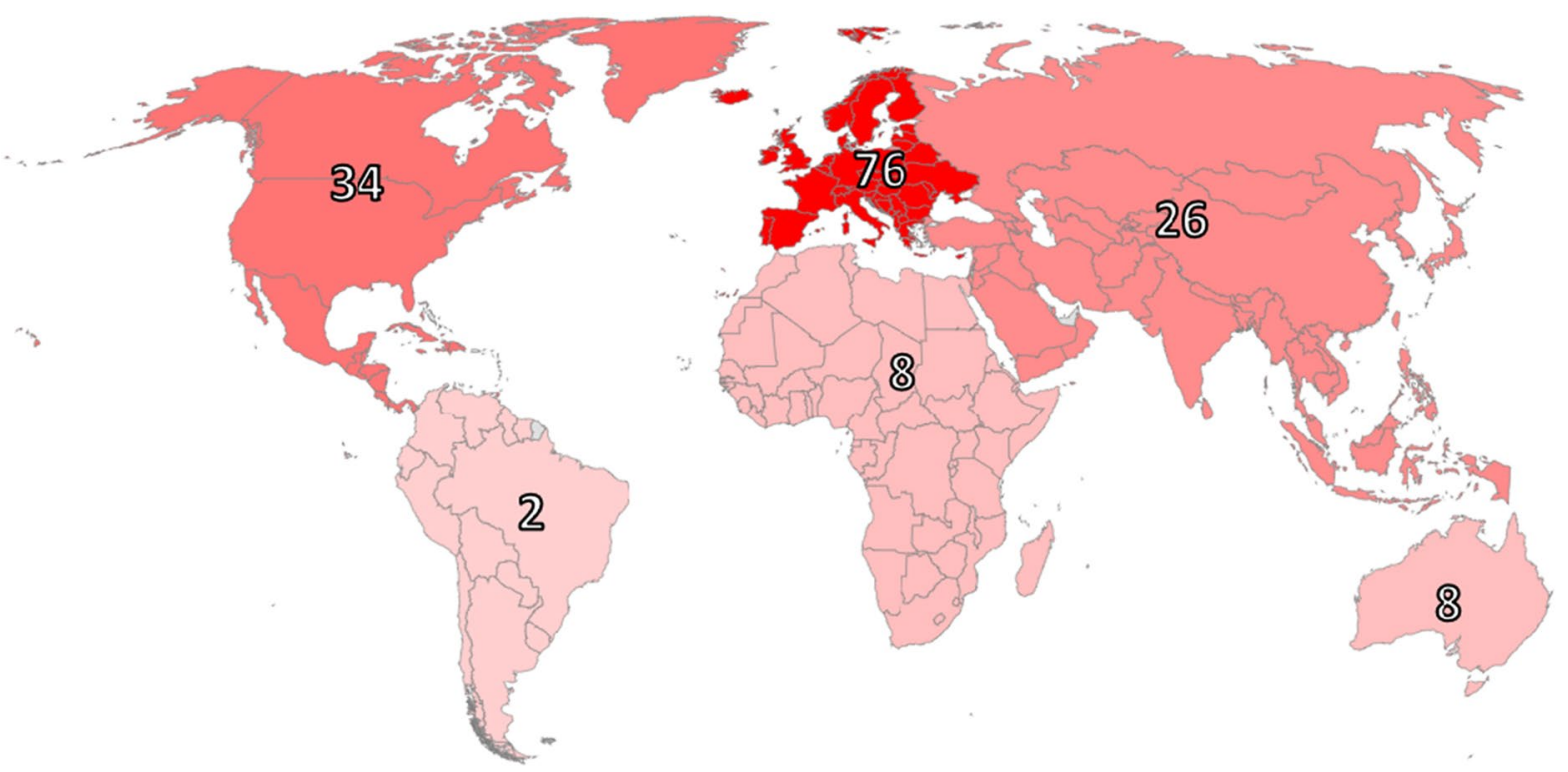

Fig. 9 The most contributing continents with respect to publications. Based on the affiliation of the corresponding author 
Fig. 10 The most contributing European countries with respect to publications. Based on the affiliation of the corresponding author

Fig. 11 Three-field plot of the building specific records found in Scopus

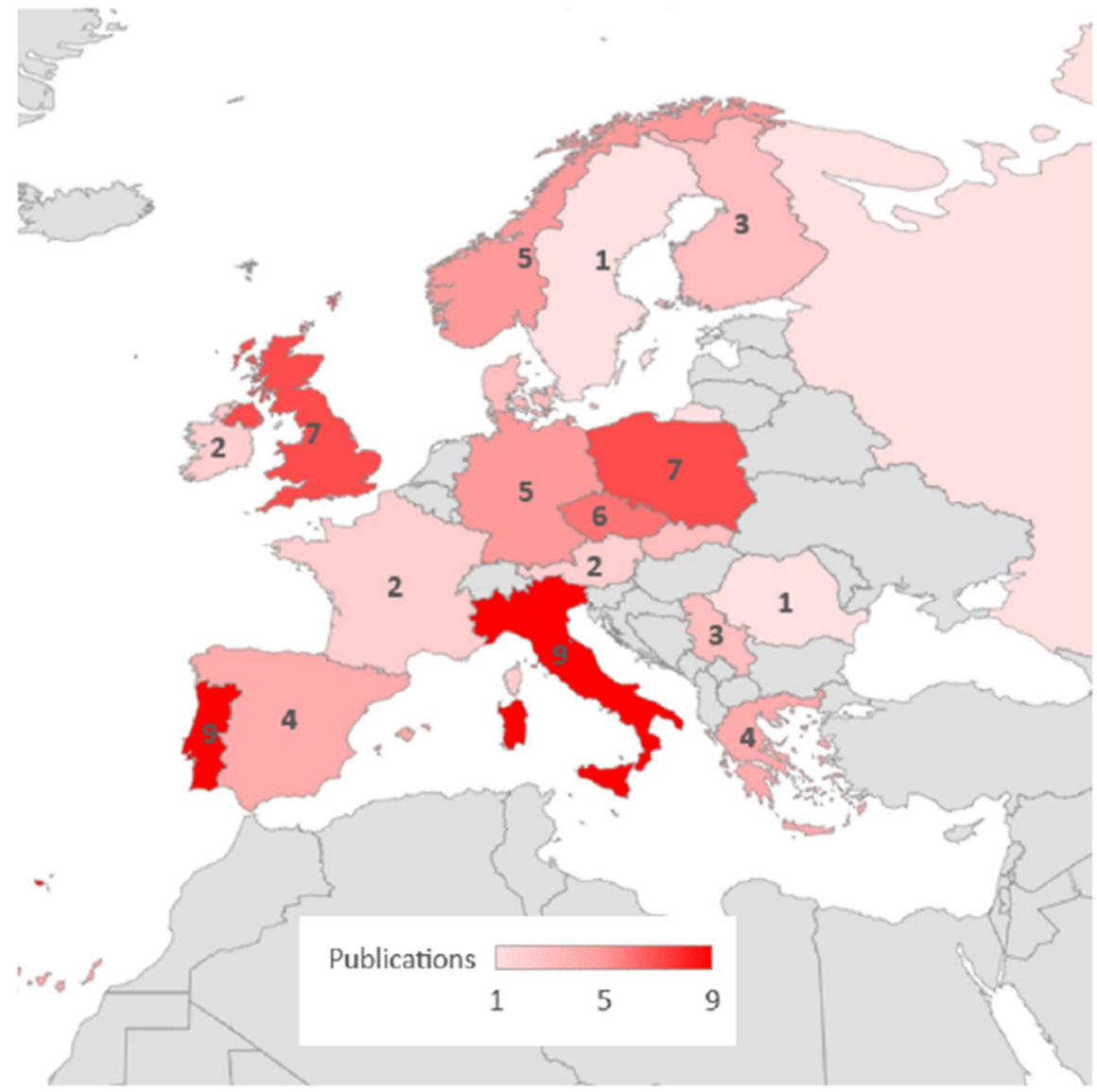

Keywords

Abstract

Source

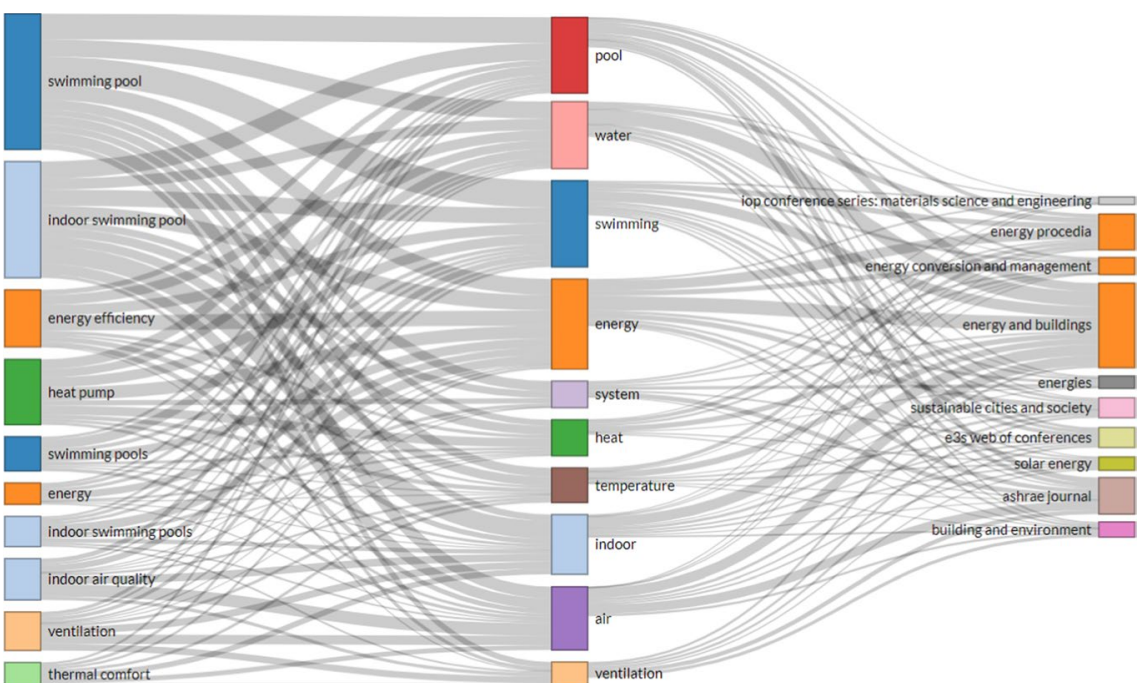


terms "swimming pool" and "indoor swimming pool." Regarding the concept of the studies, given in the field of author's keywords, the term "energy," "water," and "air" are distinguished. The scientific journal "Energy and Buildings" is once again seen to involve all of the combinations, but mostly "energy" and "water." The "ASHRAE Journal" is found to include most articles distinguished by the term "air."

Considering the Scopus dataset of HVAC and engineering specific records, and inspecting the occurrence of central terms, the following result is found:

- "Energy" occurs in $80 \%$ of the topics (title, keywords or abstract).

- "Ventilation" occurs in $30 \%$.

- "Air quality" occurs in $20 \%$.

- "Thermal comfort" occurs in $10 \%$.

This indicates that most of the publications have an energy-related approach where energy efficiency is a central part of the research.

\section{Results of thematic analysis}

With the complex thematic structure of swimming facilities, the fragmented research area found in the bibliometric analysis is expected. Due to the multiple purposes of these facilities, many issues during operation will occur as well. The primary function of the facilities is to offer the user groups swimming pools in a comfortable and harmless indoor environment. Within this task, multiple topics are present, such as thermal, acoustic, actinic, and atmospheric comfort. In addition, the water quality is crucial, with respect to temperature (thermal comfort), water treatment, and air quality affected by Disinfection By-Products (DBPs). Second, these main functions should be fulfilled without harming the building envelope (issues regarding building safety and life cycle cost), for example, preventing corrosion and condensation. Finally, these tasks should preferably be achieved with minimum energy use.

Considering these factors together frames a research area with a large potential for optimizing and improving performance. The research communities have approached all these fields to a different extent. This section summarizes some of the most important

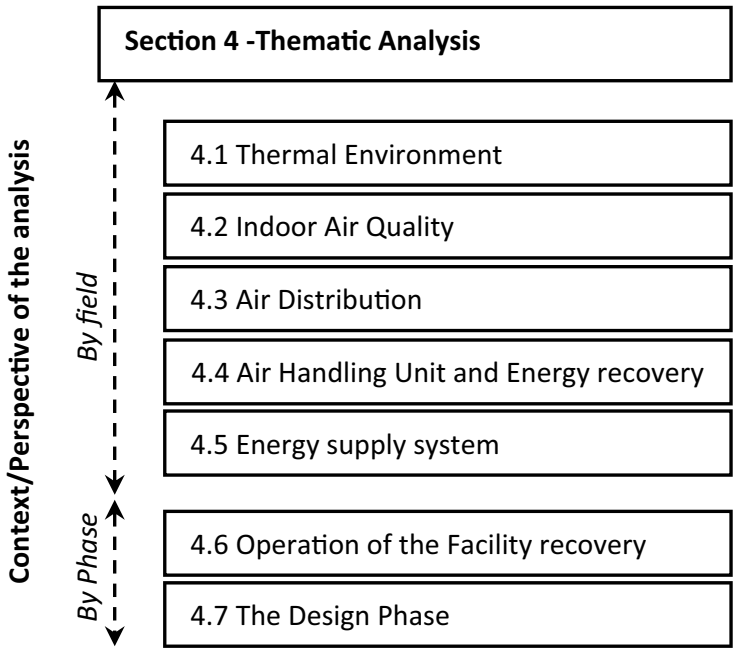

Fig. 12 Section 4-graphic table of content

research in the context of each discipline, for indoor swimming facilities. Figure 12 provides the structure of the analysis in this section.

Indoor thermal environment

When evaluating the indoor environment in a swimming facility, the complexity appears in full scale. For the thermal comfort part, the diversity of the user groups is significant and ranges from experienced swimmers using the facility for training purposes, to water activities and swimming for kindergarten children and the disabled. In addition, there are spectators and lifeguards present where the latter are present for hours. In other words, the diversity is present in both the activity level, ranging from high to low, the clo factor (from swimwear to normal clothing), as well as wet and dry bodies. Hence, the task of providing a good thermal environment for every user group is challenging (Rajagopalan \& Jamei, 2015).

Rajagopalan et al. (Rajagopalan \& Jamei, 2015; Rajagopalan \& Luther, 2013) investigated the occupants' perception of thermal comfort and found a high level of discomfort in natural and hybrid ventilated facilities in temperate climates during hot weather with the use of predicted mean vote (PMV) and thermal sensation vote (TSV). Even though the indoor environment is extreme with respect to air temperature and humidity, the thermal perception of the staff and spectators (dry bodies) was found 
to correlate well with the indoor temperatures and PMVs. For the wet bodies, the case was different. Swimmers act as multiple thermal objects during the period of presence, both with dry and wet bodies. Since the occupants' thermal comfort is a result of human heat balance (Abel et al., 2003) and wet skin is a special case, an additional evaporation term is require in the energy balance equation. This is not applied in the PMV method.

Revel and Arnesano (2014b) investigated the perception of the thermal environment in sport facilities, where a swimming pool environment, including participants with wet skin, was among the considered user group. In this study, a good correlation was found between PMV and TSV for swimmers with wet skin when applying an evaporation term in the proposed heat balance equation when calculating the PMV (Standard Norge, 2006). For this specific study, the Stolwijk model for the evaporation term (Lammers, 1978) was applied with good results. It was also shown that the PMV and predicted percentage dissatisfied (PPD) indexes can be used to evaluate the thermal perception of the swimmers and to make the facility management informed of the facility's performance with respect to thermal comfort. This may give the facility more satisfied users and also the possibility to optimize the energy performance of the facility (Revel \& Arnesano, 2014a). By continuously monitoring and evaluating, a satisfying thermal environment may be obtained through the lifespan of a swimming facility. However, measurements are no better than the total uncertainty of the measurements. For example, in Norwegian swimming facilities, the sensors are placed in the extract chamber in the central air handling unit (AHU) or in each AHU if multiple. This does not take the indoor air distribution in the facility into account (Arnesano et al., 2016) and may not display the indoor thermal environment in a proper way. Arnesano et al. (2016) showed a significant improvement in the measurements inside a swimming facility by optimizing the sensor placement. In the specific case, the conventional system performed within acceptable limits for $60 \%$ of the period, whereas the improvement with an optimized sensor placement performed satisfactorily for almost the entire period.
Indoor air quality

Indoor air quality is mainly evaluated by the level of airborne particulate matter and contaminants. The research has provided considerable knowledge regarding air quality to the HVAC community, mostly through descriptive studies. This includes studies regarding.

- Numerous disinfection by-products (Richardson et al., 2010; Weaver et al., 2009),

- Occurrence and human consequences (Shaw, 1986; Benoit \& Jackson, 1987; Kim et al., 2002; Righi et al., 2014; Lévesque et al., 2015; Zhang et al., 2015; Chowdhury, 2016; Nitter et al., 2018; Gabriel et al., 2019; Nitter \& Svendsen, 2019a),

- Formation of DBP (Jmaiff Blackstock et al., 2017; Kim et al., 2017; Fakour \& Lo, 2018),

- The impact of water treatment (Weng et al., 2012; Hansen et al., 2012; Weng et al., 2013; Spiliotopoulou et al., 2015; Nitter \& Svendsen, 2019b),

- Impact on the users and the user's uptake (Chu et al., 2013; Fernández-Luna et al., 2013; FontRibera et al., 2016; Hang et al., 2016; Parrat et al., 2012; Xiao et al., 2012).

Due to the humid environment and the ventilation intensity, dust is not found to be a problem in swimming facilities (Kic, 2016). On the other hand, DBPs from chlorine-based disinfection are associated with such facilities and of particular concern (World Health Organization, 2006). This water treatment method, which is the most common in swimming facilities, secures the absence of pathogens (viruses and fungi) in the water, which may cause severe health effects if not removed (World Health Organization, 2006). The reaction between chlorine and organic matter from the occupants, such as hair, sweat, skin cells, urine, and lotions, creates DBPs. The presence of DBPs in the poolroom has been linked to a variety of health issues (Liviac et al., 2010; World Health Organization, 2006; Manasfi et al., 2017). Within the DBP research area, the necessity of proper ventilation is often emphasized, but without any design specifications or suggestions (Berg et al., 2019; Dyck et al., 2011; Erdinger et al., 2004; Nitter et al., 2018). Due to the complexity of these kinds of HVAC systems and the need for specific ventilation, 
energy, and building physics expertise, this is not surprising. Anyway, the different studies underline the awareness regarding the ways DBPs penetrate the human skin, among which inhalation plays the most important role. It is impossible to eliminate the formation of DBP, but it can be limited by, for example, reducing the DBP precursors and diluting the pollution by enhanced air supply or improvement of the water treatment system (Manasfi et al., 2017; Ratajczak \& Piotrowska, 2019).

The traditional ventilation concepts are designed to avoid condensation on surfaces (Nitter \& Svendsen, 2019a). The air is normally supplied below the window surfaces and extracted from a centrally placed extract air grill. This concept is applied even in newly commissioned swimming facilities where the surface temperatures theoretically never will drop below the dew point (Ratajczak \& Piotrowska, 2019). Even though the DBP research community generally has not provided any specific design codes or guidelines, only emphasizing the importance of proper ventilation to minimize hazardous inhalation, some of the studies have recommendations.

The performance of the ventilation system, in relation to its intended function, depends on the fresh air supply and air distribution. The traditional design has been exclusively focused on protection of the building construction and keeping the indoor environment within a given range of temperature and humidity. Since the main source of air pollution in swimming facilities is the water surface, there is consensus that the design of the ventilation system is one of the most important tasks in the work regarding improving the indoor air quality for swimmers (Berg et al., 2019; Nitter \& Svendsen, 2019a; Ratajczak \& Piotrowska, 2019; Saleem et al., 2019).

In the present studies, the operation of the ventilation system is rarely reported. While some report a fresh air share between 20 and $100 \%$ of the total air flow and a maintenance staff demonstrating a great degree of uncertainty (Gabriel et al., 2019), others report 4 to 6 air changes per hour $(\mathrm{ACH})$ and a ventilation control strategy based on controlling the air flow by both temperature and humidity, aiming to prevent condensation, and due to an annual large enthalpy difference (Nitter \& Svendsen, 2019b). Another study reported that details regarding the ventilation system were not known, neither the air flow rate nor the system topography (Erdinger et al.,
2004). This lack of technical knowledge is of course expected due to the complexity of the facility and the technical system. Consequently, this underlines the need for interdisciplinary cooperation between the HVAC and DBP research fields to get precise design guidelines which can make a difference.

Despite the general lack of practical and useful recommendations for design parameters and system topography, exceptions exist. There are three possible ways to improve the air quality (Ratajczak \& Piotrowska, 2019):

1. Reduce precursors,

2. Apply better disinfection methods,

3. Improve ventilation in the occupied zone.

Reduce precursors DBPs are an unintended consequence when the aim is to inactivate pathogens in swimming pools. Since many of the DBPs found in swimming pools are formed by the reaction of disinfectants, like chlorine, and natural organic matter from humans (Richardson et al., 2010), an obvious priority toward improved air quality is to reduce the precursors. Since this is a result of human hygiene, such as showering before swimming and avoiding the discharge of urine during swimming, the task of reducing this is not trivial or technical, but a socioanthropological task where guiding/informing and possibly the layout of the shower room play an essential role. Even though urine is sterile itself, mixing with pool water represents a public health concern. Urine contains many compounds that can react with disinfectants, as chlorine, and may form DBPs (Jmaiff Blackstock et al., 2017). Since the potential limitation of the introduction of organic matter may not have an immediate effect on the DBP levels due to the slow reactions with chlorine, the facility management should emphasize continuous public awareness campaigns (Parrat et al., 2012).

Apply better disinfection methods Although the precursors are minimized, a complete elimination of organics is impossible. Urine has a massive chloroform DBP formation potential (Berg et al., 2019) which is likely to end up in the pool's air (Berg et al., 2019). In addition, results have shown that removing the volatile DBP trichloramine across the water treatment train is not a feasible strategy due to the high 
formation rate in the pool (Skibinski et al., 2019). Thus, the ventilation concept and fresh air supply for the facility are crucial to reduce the negative health impacts for the occupants. The layout of the water treatment train is of major importance in minimizing the harmful DBPs. For example, the use of granular activated carbon filtration is shown to remove trihalomethane (THM), and the use of UV treatment is shown to increase the air concentration of THMs (Nitter \& Svendsen, 2019b).

Improve ventilation in the occupied zone Removing airborne pollutants can be done by either mixing ventilation concepts, by source capture through replacement ventilation, or a combination of both. Traditionally, the ventilation systems in Norwegian swimming facilities are based on mixing ventilation with low ventilation effectiveness, where the air is supplied in the vicinity of the glazing façade and a centrally placed extract air grill (Nitter \& Svendsen, 2019a; Polak, 2008b). The concept is based on the perception that the main purpose of the ventilation system is to prevent condensation on the inner surface, supply sensible heat to the facility, and to dehumidify the air. The concept is found in Norwegian guidelines, as well as foreign references and standards, where the importance of stagnant air or low air velocities by the water surface is emphasized (Norges byggforskningsinstitutt, 2003; Polak, 2008a; ASHRAE, 2015; Bøhlerengen et al., 2004; Saunus, 2008; Standard Norge, 2019a). This is due to the air velocity impact on the pool evaporation rate. Since the space above the water surface is the occupant zone by definition, the traditional ventilation concept provides low ventilation efficiency and consequently relatively high values of DBP have been observed (Nitter et al., 2018). However, this design is in accordance with the present HVAC guidelines.

\section{Air flow distribution}

The air distribution in a swimming facility is of major importance. A properly designed system will supply fresh air to the breathing zones, remove airborne contaminants and disinfectant by-products, and prevent condensation, corrosion, and stratification (Lochner \& Wasner, 2017). In the case of the latter, improper design may cause severe damage to both the building envelope and structures, like staircases, diving platform towers, handrails, and the technical equipment. In combination with adverse material properties, pitting corrosion may occur (Sedek et al., 2008; Szala \& Łukasik, 2018).

Regarding the building envelope, exfiltration and infiltration may result in moisture accumulation that conceal deterioration of the building materials (Ananian et al., 2019). Condensation inside the facility may also cause corrosion, and in combination with poor ventilation efficiency the prevalence of fungi may occur (Viegas et al., 2010). The ventilation system should also maintain the thermal and hygroscopic environment within the preferred range and minimize the level of DBPs. There is consensus within the research community regarding the importance of good ventilation in order to avoid harmful environment for the pool users (Berg et al., 2019; Manasfi et al., 2017; Nitter \& Svendsen, 2019a; Nitter et al., 2018; Ratajczak \& Piotrowska, 2019; Zhang et al., 2015). Due to the complexity of swimming facilities and the multi-functionality of the ventilation system, a refinement is not straightforward. There are three possible approaches to improve the ventilation concept:

1. Improve ventilation efficiency (distribution),

2. Increase fresh air supply (dilution),

3. Remove DBP by source (concept).

Improving ventilation efficiency must be carried out by supplying more fresh air into the occupancy zone, which is against the present international guidelines, where air flow in the vicinity of the water surface is discouraged. Despite this, Cavestri and Seeger-Clevenger (2009) found a top-level ventilation concept in combination with a deck-level exhaust system to be successful in maintaining DBPs at low levels (Cavestri \& Seeger-Clevenger, 2009; Baxter, 2012). By utilizing the physical properties of one of the most important DBPs, trichloramine, the system showed low levels of this DBP with the same fresh air flow rate as suggested by ASHRAE (2015; ASHRAE \& ANSI, 2013). The concept is based on a principle of displacement of the polluted layer of air above the water surface, and the exhaust air is completely extracted from the facility, without being included in the air recirculating system, which is usual in swimming facilities. However, some technical issues regarding the 
energy efficiency of the facility must be solved when implementing this ventilation design.

As a part of the increased focus on reducing energy consumption in the building industry during the last decade, the Norwegian legislation has approached high energy efficiency building codes and the passive house concept (Standard Norge, 2012; The Norwegian Ministry of Local Government and Modernisation, 2017). This includes swimming facilities as well. An improved building standard reduces the heating demand and exfiltration/infiltration losses, increases the inner surface temperature, and reduces disparity in air supply/extraction. Rojas and Grove-Smith (2018) have taken this into account in their numerical study of possible ventilation concepts in energy-efficient swimming facilities carried out with CFD simulations. While the traditional high recirculation air change rate in swimming facilities is due to the need for good air distribution throughout the entire hall in order to avoid condensation and obtain a satisfying indoor thermal environment, the air change rate may be reduced and air circulation may be avoided (Rojas \& Grove-Smith, 2018). The proposed optimal system, a "top level supply-low level extract" system with swirl diffusers with vertically discharging air, achieved the best air exchange and contaminant removal efficiency. Despite the uncertainty with an unvalidated CFD model, the importance of the low vertical location of the extract air opening was emphasized, as Cavestri and SeegerClevenger did (Cavestri \& Seeger-Clevenger, 2009; Baxter, 2012). Regarding the supply air design in general, Limane et al. found improved air quality, improved thermal comfort, and reduced air stratification and age of air by increasing the air impulse and redirecting the air jet toward the occupied zone (Limane et al., 2018).

The complexity of the air supply and air flow patterns in large halls is considerable. Several microzones may easily occur, with stratification and dead spots, which can lead to severe corrosion, as previously mentioned. Areas with swimmers, people on the deck, spectator areas, and exteriors that need condensation and corrosion prevention need to be taken into account in the design (Lochner \& Wasner, 2017). Ratajczak and Szczechowiak (2020) did just this in their study, while zoning the swimming facility with three virtual zones, each with dedicated ventilation systems: spectator zone, wall and roof as well as a source capture system for the occupant zone in the pool environment. This solution was proven to perform with a possible energy savings of maximum $36 \%$ as well.

\section{Numerical investigation}

Regarding investigation of air flow distribution, several numerical and experimental studies have been carried out, each with a distinctive approach. The phenomena of water evaporation and how to implement this in a CFD model was treated by both Ciuman and Lipska (2018), Blázquez et al. (2017), and Blázquez et al. (2018). Here, empirical relationships and the use of predefined boundary conditions were proposed. When modeling the indoor environment of a swimming facility, the calculated evaporation rate is of major importance due to its impact on air density, the dew point, and, last but not least, the overall energy use in the facility.

Lebon et al. (2017) used a validated zonal model developed in TRNSYS to investigate the indoor airflow patterns and occupants' perception of thermal comfort. They documented inadequate air renewal in the occupant zone and poor thermal comfort, with a too hot and humid environment in this specific pool hall including a semi-Olympic swimming pool. Limane et al. (2017) further investigated this specific facility by the weather effect on the indoor environment and documented a very small impact. Furthermore, the effect of the swimmers in the swimming pool was evaluated and found to be of great importance for the indoor environment. The main advantageous effect was found to be less stratification and better air mixing, and the adverse effect was increased specific humidity in the swimming zone. This underlines one of the main obstacles when modeling air flow in swimming facilities, where most studies present results from cases without occupant behavior.

Air handling unit and energy recovery

Along with the ventilation concept and the fresh air supply, the air handling and the mechanical design have a considerable impact on energy use. The AHU plays a central role in swimming facilities since it maintains the required thermal and atmospheric indoor environment and is an important tool to maintain safety (Standard Norge, 2019a). Since a standard AHU for a swimming facility provides temperature and humidity control as well as atmospheric control, the main part of the internal energy flow passes through the AHU, due to the absorbed moist air related to the evaporation. As a result of this, 
the design of modern swimming facility-dedicated AHUs includes the mechanical concept, the control system, and the energy recovery concept. The latter normally includes heat transfer between the air and water circuits, which is crucial for maximizing energy recovery.

For climatization and ventilation of swimming facilities, there are mainly two concepts for dehumidification and air supply:

1. Outdoor air dehumidification-maximizing fresh air supply,

2. Mechanical dehumidification-minimizing fresh air supply by refrigeration dehumidification.

The first concept, combined with mechanical energy recovery and dehumidification, is most widely used in Scandinavian countries (Johansson \& Westerlund, 2001). These systems have been investigated in multiple studies, in several setups with heat pumps in several layouts as well as absorption systems with absorbent (Johansson \& Westerlund, 2001; Liu et al., 2014; Qiu \& Riffat, 2010; Ratajczak \& Szczechowiak, 2020; Sun et al., 2011). Johansson and Westerlund (2001) proved the importance of a heat recovery system in the air circuit in their study and reported approximately $20 \%$ reduction in the total energy demand for this application. As Liu et al. concluded (Liu et al., 2014), Johansson and Westerlund also identified an absorption system to be the most efficient of the two concepts. Due to the well-established technology in the market, the heat pump system should normally be the preferred equipment in new projects (Johansson $\&$ Westerlund, 2001). This recommendation is based on the importance of optimal continuous operation of equipment that is both operator-friendly and supplied with well-defined supplier-directed responsibilities due to the overall functioning over the lifetime span of operation.

The energy supply system

The energy systems in swimming facilities are complex even in the basic layout; they include water circuits, air circuits, makeup-water system, and often multiple heat pumps and complex control strategies due to the demanding indoor environment and the need to control the evaporation phenomena. Since the energy performance of the swimming facility depends both on the technical layout and the presence of a heat recovery system (Kampel et al., 2014), predesigned energy recovery systems are available on the market. These are for the heat recovery of exhaust air and waste water. Generally, the design of these systems requires a highly conscious designer, with respect to the layout to the selection of equipment since high energy use is related to weaknesses in the building design and maintenance (Kampel et al., 2016). Kampel et al. found that the Norwegian swimming facilities had an excessive energy use, approximately $30 \%$ above the expected level (Kampel et al., 2013). In addition, they found considerable variation in the specific energy use. Comparing this to the specific energy use per visitor, presented by Rajagopalan (2014), no consensus regarding energy use is observed. There may be many reasons for this, but the operation of the facility is obviously one of them.

The dispersion in energy use and the complexity of the facility underline the importance of an operational and maintenance tool for the operation staff. Kampel et al. emphasized the importance of this by using benchmarking in operation for identifying operational irregularities. He proposed a "key performance indicator" based on energy usage data for 43 Norwegian swimming facilities (Kampel et al., 2016). This general approach can be regarded as a "first help aid" for operating swimming facilities because of its general approach and the accuracy of the method. While Kampel et al. claimed that overall water usage is the most correlated variable to the energy usage, the literature differs in the use of "key performance indicator" for energy use in swimming facilities. Other studies did not find any strong correlation to water usage (Duverge et al., 2018) but found the strongest correlation to the bather load and the number of opening days (Nitter et al., 2019), or referring to usable area $\left(\mathrm{kWh} / \mathrm{m}^{2}\right.$.a) (Rajagopalan, 2014; Swim England, 2016) or water surface area (kWh/ws.a) (Trianti-Stourna et al., 1998). This indicates that this benchmarking tool, based on statistical data from multiple facilities, could not be the optimal solution as an operational guidance tool for securing optimal operation of the facility. This is mainly due to the accuracy and the variety of facility types, and the fact that the concept of benchmarking is "looking backwards" and comparing annual energy use of existing swimming facilities to avoid operation disruption in new facilities. 
Operation of the facility

The overall energy consumption of the building and the consequent environmental impact is dependent on the operational phase of the building (Rincon et al., 2013), and this should be emphasized. The lack of supervision of a building's performance after commissioning and during the operational stage as well as the complexity of rating systems are identified as some of the major obstacles associated with building performance assessment systems (Namini et al., 2014; Rincon et al., 2013). Despite this, the literature generally lacks rating systems as operational support, both as tactical and operational tools (Ruparathna et al., 2017). In swimming facilities, the complexity of the rating system and the impact of the operation may be expected to be substantial. The consequence of inappropriate operation of the HVAC system in swimming facilities may cause problems like degradation of equipment and the occurrence of the sick building syndrome (Pietkun-Greber \& Suszanowicz, 2018), in addition to increased water and energy usage.

The complexity of creating such a rating system for swimming facilities is well illustrated by the estimation of the energy use, which is crucial in a rating system for this building category. Several researchers have proposed calculation methods for this by introducing physical models ( $\mathrm{Lu}$ et al., 2015), machine learning tools (Yuce et al., 2014), and building performance simulation tools like IDA ICE (EQUA Simulation AB, 2020) or TRNSYS (Calise et al., 2018; Mancic' et al., 2014), each represented by pros and cons. However, none of these calculation methods can be easily implemented into average operation management.

\section{The design phase}

Besides the importance of the facility operation, the design phase is crucial for the performance of the facility. The engineers design a system that aims to fulfill the building-defined energy usage ambitions and the user demand regarding the indoor environment. This task is a multi-objective optimization problem including technical issues and the construction of the building envelope where holistic and indepth knowledge is required. For example, research has established that an improvement in the thermal properties of the building envelope is proven to have the potential of reducing the energy consumption by $20 \%$, considering a refurbishment project (Isaac et al., 2010). The dependence between the indoor environment and energy use is also found by Westerlund et al. (1996), where the air temperature and humidity had a considerable impact on energy use. Due to the influence of an open water surface, the indoor temperature may have the opposite effect on the energy use compared to conventional "dry" buildings. Depending on the type and extent of the heat recovery system in the AHUs, the temperature level will affect the energy use differently. A system without a heat recovery system will profit from a relatively high indoor air temperature (Johansson \& Westerlund, 2001) whereas a concept with a highly developed heat recovery system will profit from a lower indoor air temperature. This is due to the interaction between thermal losses in the swimming hall, the air flow losses, and evaporation from the pool surface. Ribeiro et al. treated this interaction in their work, where the use and selection of set-point temperature and humidity was investigated and discussed (Ribeiro et al., 2011, 2016). By introducing alternative control variables, dew point and wet bulb, as well as alternative ranges, they proved an energy cost savings for the specific case study of about $8 \%$ (Ribeiro et al., 2016). This indicates a large energy savings potential just by adjusting the software for the building energy management system.

The control system and the choice of controller is another important topic. Normally, the HVAC system is equipped with P, PI, and PID controllers, depending on the purpose. The use of predictive control, in combination with solar systems, with early shut-off, proved to reduce the energy demand by approximately $20 \%$ and the fuel consumption by approximately $40 \%$ (Delgado Marín et al., 2019). This improvement was due to the successful task of maximizing the applied solar energy into the system. The concept of predictive control is especially suited for making the system operate with an economically optimal regime, where the heat supply can be directed to periods with high electricity charges (Zemtsov et al., 2017).

Taking into consideration the thermal mass of the swimming pool, the proper selection of the control parameters is associated with reduced operational cost, similar to the case for outdoor swimming pools (Venkannah, 2002). This thermal mass may either be utilized in the energy plant locally, with the purpose of reducing energy consumption and for effect peak 
shaving purposes (Woolley et al., 2011) or for peak shaving for district heating systems for neighborhoods (O. Kim et al., 2018).

When taking the pool into account, with an active approach as mentioned above, the importance of evaporation cannot be underestimated. The consequences of misjudging the magnitude of the evaporation rate will result in either a dysfunctional HVAC system (in case of the design phase) or excessive energy use (if uncontrolled in the operation phase). Due to the complex nature of these phenomena, calculation is not a straightforward task. Numerous articles have been published over the last century regarding this subject, all of them based on Dalton's first empirical investigation that determined the law of partial pressure which was published in the early nineteenth century (Dalton, 1802). Although there is a lack of consensus regarding one particular calculation method, some major methods stand out.

The widely known correlation which Carrier proposed in 1918 (Carrier, 1918) was based on results from a set-up with an unoccupied water surface and by experiments using forced air flow. Even though the set-up only included forced convection, the equation has also been used for natural convection by setting the velocity term to zero. The equation has been widely used throughout the century for all sorts of facilities, and applied in the ASHRAE handbooks (ASHRAE, 2015), where an additional activity factor is applied to the equation.

Smith et al. investigated the evaporation rate for both indoor and outdoor swimming pools, as well as occupied and unoccupied pools (Smith et al., 1993, 1994, 1998). They confirmed the form of the Carrier equation but proposed a correction factor for unoccupied cases and an activity factor for the occupied cases. They found that the Carrier equation overpredicted the evaporation rate when applied in cases with unoccupied pools.

Hanssen and Mathisen (1990) performed experiments in a school swimming pool in Trondheim, Norway, and proposed a semi-empirical equation for estimation of the evaporation rate. The equation has been important for Norwegian engineers since it was published in 1990, and has been referred to in the academic literature by Stensaas (1999) and in the NBI engineering guidelines (Norges byggforskningsinstitutt, 2003). The equation is valid for both occupied and unoccupied pools using a proposed activity factor. Even though the activity factor is proportional to the number of swimmers in the pool, it was emphasized in the study that the evaporation rate increases more like a step function, even with a few swimmers present.

During the last three decades, Shah has published several articles regarding his work on evaporation correlations (Shah, 1992, 2002, 2003, 2008, 2012, 2013, 2014). The equations presented are based on physical phenomena, theory, and empirical data. Shah validated his formulas with all available test data and compared the accuracy with several present correlations (Shah, 2014). His equations and calculation algorithms predicted evaporation for unoccupied and occupied pools with a mean deviation of approximately 21 and 16\%, respectively (Shah, 2012).

Other empirical equations of major importance to industry are provided by the VDI guidelines (Verein Deutscher Ingenieure, 2010). VDI applies to heating, room air, sanitary installations, and electrical systems in public indoor swimming pools and for Germany can be considered as ASHRAE is for the USA.

\section{Prediction of performance}

Several studies regarding evaluation of the present evaporation equations have been carried out. While Shah (2014) evaluated the performance in his own algorithm to be the most accurate, Ciuman and Lipska (2018) found the most accurate correlation to be the VDI correlation (Verein Deutscher Ingenieure, 2010), by comparing the performance of Carrier (1918), Smith et al. (1993), Shah (2014), ASHRAE (2007), VDI (Verein Deutscher Ingenieure, 2010) as well as Biasin and Krumme (1974). Li and Heiselberg (2005) found that the ASHRAE correlation (ASHRAE, 2007) gave a good prediction for higher occupancies, while Shah's correlation for unoccupied pools (Shah, 2002) and occupied pools (Shah, 2003) gave the best prediction. This underlines the uncertainty when dealing with evaporation. This challenges the designer of the HVAC system because this uncertainty affects the overall system efficiency. Taking into account the overall complexity when including the energy plant and the ventilation system when predicting the annual energy consumption, the use of building performance simulation (BPS) tools is crucial for optimizing and sizing the systems. Concerning prediction of evaporation in multizone 
network, the BPS tool IDA ICE (EQUA Simulation $\mathrm{AB}, 2020)$ has implemented the ASHRAE equation (ASHRAE, 2007) while Transsolar's TRNSYS pool add-on (Auer, 1996) has applied the VDI equation for occupied pools (Verein Deutscher Ingenieure, 2010).

Regarding the design of the energy plant, improvements regarding the layout can be done by optimizing the configuration. An optimal configuration and capacity of a polygeneration system gives good solutions for a specific case, but are often based on the present energy demand (Mančić et al., 2018). The task is not trivial and knowledge with respect to detailed information regarding the performance is crucial (Luo et al., 2019). There are numerous possible sources; some are especially adapted to the specific building and location and some are not. For example, the use of a solar roof has been proved successful (Archibald, 2017) as well as buildings interacting with each other and sharing energy (Abo Elazm \& Elsafty, 2011; Kuyumcu et al., 2016).

Chow et al. (2012) used TRNSYS (Klein et al., 2017) to investigate the use of a solar-assisted heat pump for a public swimming center located in Hong Kong. They found that the installation performed well with an economical payback period less than 5 years. Even though tropical and subtropical areas are assumed to be favorable, solar energy systems are not the preferred energy source for public swimming facilities in all areas (Fuller et al., 2017). Fuller et al. (2017) assessed the viability for a solar heating system in the southern part of Australia and found the investment to be relatively favorable with a payback of about 7 years. However, the system was found not to be common in public facilities, where the barriers were unchanged for the last 30 years. These studies illustrate the need of a BPS tool in the design phase.

Along with the improvement in the building standard for the whole building stock, and the consecutive reduction of the energy consumption, the implementation of power-demanding devices has been substantial. Due to this, peak demand tariffs have been introduced. This encourages the end users to reduce their power demand. By applying demand control strategies, studies have shown a reduced peak power cost by approximately $15 \%$ by the use of battery storage in a medium-sized swimming facility which includes a grid-connected photovoltaic system (Berglund et al., 2019). The potential for optimizing these kinds of facilities seems substantial but is highly complex.
Consequently, software and modeling techniques for the engineering community must be developed further.

\section{Conclusions}

This paper presents a review of the research in the area of swimming facilities in the context of heating, ventilation, and air conditioning (HVAC). Different aspects of swimming facilities have been covered including air quality, ventilation, and energy performance. The contribution in each field has been presented as well as the research focus. The understanding of swimming facilities as a building type is a highly complex task as it is a system involving numerous interacting disciplines. The aim of this paper has been to create a better understanding of the topic and reveal the weak spots in the current state of the art.

\section{Air quality and ventilation}

The research field of disinfection by-products (DBPs) in swimming facilities appears to be mature and has evolved to be the most important research area during the past decade given the largest number of publications.

In general, the gap between research and engineering is wide in this field. If designers are to use the findings related to this topic, precise recommendations must be provided and the close relation to the interaction with the HVAC system must be precisely described. Future studies that aim to provide knowledge for improved design should be carried out by multidisciplinary research teams in order to ensure that the results are possible to implement and interpret in the context of HVAC and system architecture. However, there is consensus that DBPs in indoor air in swimming facilities should be dealt with by an effective ventilation system:

- The ventilation concept of source capture has proven to perform well (Cavestri \& Seeger-Clevenger, 2009; Baxter, 2012), even though this design is in contradiction to national and international guidelines which recommend to avoid, or minimize, the air movement in the swimmers' breathing zone, due to its effect on evaporation. However, apply- 
ing the concept of source capture leaves the challenge to the present design of AHUs with large internal flow of recycled air, which must be modified in order to ensure high energy efficiency for the facility.

- The fresh air flow rate is found to correlate with the dilution of contaminates and the concentration of DBPs (Nitter \& Svendsen, 2019a). However, no consensus is found regarding the recommended fresh air flow rate. Some studies call for "100\% fresh air" (29), another "a large air volume" (Parrat et al., 2012). A few studies recommend a customized control system for the fresh air supply by including variables like "water quality" and "bather load" (Nitter \& Svendsen, 2019a). Stateof-the-art AHUs dedicated for swimming pools have complex control systems where the supply air flow rate is decided by variables like operating mode, supply air temperature, extract air temperature, air humidity, and heat supply. New additional variables must be precisely evaluated due to the increased complexity, the additional risk of excessive energy use, and the overall vulnerability of the system. In general, an increased fresh air supply will reduce indoor humidity and result in greater evaporation and energy use, in addition to the impact on thermal comfort.

- The lack of prediction models for the generation rate of DBPs has been identified since this is an important index when designing ventilation systems. Present guidelines and regulations, like the national guidelines (Bøhlerengen et al., 2004; Norges byggforskningsinstitutt, 2003; Polak, 2008b), international guidelines (ASHRAE \& ANSI, 2013; Verein Deutscher Ingenieure, 2010; ASHRAE, 2015; World Health Organization, 2006; Standard Norge, 2019b), and Norwegian codes (The Norwegian Ministry of Local Government and Modernisation, 2017; The Norwegian Ministry of Labour and Social Affairs, 2011), are all divergent with regard to recommendations, and a proper calculation tool for optimized fresh air flow rate should therefore be developed.

In addition to the abovementioned key elements and considering that a complete stop of the applied DBP's precursors is unattainable, a hygienic control and improved water treatment should be emphasized in swimming facilities.

\section{Energy}

Several studies have treated alternative control strategies in swimming facilities and emphasized the potential in the building energy management systems (BEMS). For example, the use of alternative control variables like dew point and wet bulb temperature in alternative ranges proved an energy cost savings of about $8 \%$ for the specific case (Ribeiro et al., 2016). This indicates a large energy savings potential only by adjusting the software for the BEMS. The concept of predictive controls has also proved to be especially suited for making swimming facilities with solar systems operate with an economically optimal regime due to the thermal mass of the pool. However, the research field of energy systems in swimming facilities in cold climates is found to lack research on solar energy applications despite the considerable potential represented by the constant high electric load and the large thermal mass represented in the pool.

The system design defines the operational boundary constraints. Due to the multiple disciplines represented in the building, the need of predicting and optimizing the performance is considerable, both by means of dynamic and steady-state simulations considering the overall energy performance of the facility. This also includes modeling the complex phenomena of evaporation where there is a lack of consensus in the research.

\section{Operation}

Even a well-designed swimming facility is no better than its operation. The operation of swimming facilities is a multi-objective optimization problem that requires tactical and operational management. The probability of operational failure is substantial if only annual energy consumption and water usage measurements are included in the operators' benchmarks for the facility. The literature lacks benchmarks and rating systems, and both indexes and easily implementable methods should be developed. A rating system, as an operational tool, would ensure better operation concerning the facility's primary functions, the indoor environment, and the energy use.

Acknowledgements This work is a part of a doctoral project entitled "Optimizing Energy and Climate Systems in Buildings 
with Swimming Facilities," which is carried out as a cooperation project between the Centre for Sport Facilities and Technology at the Norwegian University of Science and Technology (NTNU) in Trondheim, Norway, and the engineering company COWI AS. The project is funded by COWI AS, The Research Council of Norway and COWIFonden.

Funding Open access funding provided by NTNU Norwegian University of Science and Technology (incl St. Olavs Hospital - Trondheim University Hospital).

\section{Declarations}

Conflict of interest The authors declare no competing interests.

Open Access This article is licensed under a Creative Commons Attribution 4.0 International License, which permits use, sharing, adaptation, distribution and reproduction in any medium or format, as long as you give appropriate credit to the original author(s) and the source, provide a link to the Creative Commons licence, and indicate if changes were made. The images or other third party material in this article are included in the article's Creative Commons licence, unless indicated otherwise in a credit line to the material. If material is not included in the article's Creative Commons licence and your intended use is not permitted by statutory regulation or exceeds the permitted use, you will need to obtain permission directly from the copyright holder. To view a copy of this licence, visit http://creativecommons.org/licenses/by/4.0/.

\section{References}

Abel, E., Nilsson, P.-E., Ekberg, L., Fahlén, P., Jagemar, L., \& Clark, R., et al. (2003). Achieving the desired indoor climate-energy efficiency aspects of system design: Studentlitteratur.

Abo Elazm, M. M., \& Elsafty, A. F. (2011). Experimental investigation of different heat recovery systems in leisure center and its effect on $\mathrm{CO} 2$ emission. [Article]. International Review of Mechanical Engineering, 5(5), 927-932.

Ananian, J. S. D., Fu, T. S., \& Gabby, B. A. (2019). Detrimental effects of air leakage on building enclosure performance: energy consumption, occupant comfort, and moisture accumulation. In T. Weston, K. Nelson, \& K. S. Wissink (Eds.), Whole building air leakage testing and building performance impacts (Vol. 1615, pp. 38-60). American Society for Testing and Materials Selected Technical Papers.

Archibald, J. P. (2017). Low temperature energy recovery designs. Strategic Planning for Energy and the Environment, 37(2), 69-79. https://doi.org/10.1080/10485 236.2017.11907883

Aria, M., \& Cuccurullo, C. (2017). bibliometrix: An R-tool for comprehensive science mapping analysis. Journal of Informetrics, 11(4), 959-975. https://doi.org/10. 1016/j.joi.2017.08.007

Arnesano, M., Revel, G. M., \& Seri, F. (2016). A tool for the optimal sensor placement to optimize temperature monitoring in large sports spaces. [Article]. Automation in Construction, 68, 223-234. https://doi.org/10. 1016/j.autcon.2016.05.012

ASHRAE. (2007). HVAC Applications handbook.

ASHRAE. (2015). Applications handbook. Refrigerating and Air-Conditioning Engineers: American Society of Heating.

ASHRAE, \& ANSI. (2013). Standard 621-2013 Ventilation for acceptable indoor air quality. Refrigerating and Air-Conditioning Engineers Inc: American Society of Heating.

Auer, T. (1996). TRNSYS - Type 144: Assessment of an indoor or outdoor swimming pool. https://www.sel. me.wisc.edu/trnsys/components/type144-manual.pdf. Accessed 20 Sept 2020.

Baxter, R. C. (2012). Designing for IAQ in natatoriums. (TECHNICAL FEATURE). ASHRAE Journal, 54(4), 24.

Benoit, F. M., \& Jackson, R. (1987). Trihalomethane formation in whirlpool SPAs. [Article]. Water Research, 21(3), 353-357. https://doi.org/10.1016/0043-1354(87)90215-6

Berg, A. P., Fang, T. A., \& Tang, H. L. (2019). Unlocked disinfection by-product formation potential upon exposure of swimming pool water to additional stimulants. [Article]. Frontiers of Environmental Science and Engineering, 13(1), https://doi.org/10.1007/s11783-019-1098-3.

Berglund, F., Zaferanlouei, S., Korpas, M., \& Uhlen, K. (2019). Optimal operation of battery storage for a subscribed capacity-based power tariff prosumer-a Norwegian case study. [Article]. Energies, 12(23), https://doi. org/10.3390/en12234450.

Biasin, K., \& Krumme, W. (1974). Water evaporation in the indoor swimming pool. (in German). Electrowaerme International, 32(A3), A115-A129.

Blázquez, J. L. F., Maestre, I. R., Gallero, F. J. G., \& Gómez, P. Á. (2017). A new practical CFD-based methodology to calculate the evaporation rate in indoor swimming pools. [Article]. Energy and Buildings, 149, 133-141. https:// doi.org/10.1016/j.enbuild.2017.05.023

Blázquez, J. L. F., Maestre, I. R., Gallero, F. J. G., \& Gómez, P. Á. (2018). Experimental test for the estimation of the evaporation rate in indoor swimming pools: Validation of a new CFD-based simulation methodology. Building and Environment, 138, 293-299. https://doi.org/10.1016/j. buildenv.2018.05.008

Bøhlerengen, T., Mehus, J., Waldum, A., Blom, P., \& Farstad, T. (2004). Byggforsk håndbok 52: Bade og svømmeanlegg. Norges Byggforskningsinstitutt.

Calise, F., Figaj, R. D., \& Vanoli, L. (2018). Energy and economic analysis of energy savings measures in a swimming pool centre by means of dynamic simulations. Energies, 11(9), 2182. 2127 pp.https://doi.org/10.3390/ en11092182

Carlucci, S., De Simone, M., Firth, S. K., Kjærgaard, M. B., Markovic, R., \& Rahaman, M. S., et al. (2020). Modeling occupant behavior in buildings. Building and 
Environment, $\quad$ 174,https://doi.org/10.1016/j.buildenv. 2020.106768.

Carrier, W. H. (1918). The Temperature of Evaporation. ASHVE Transaction, 24, 25-50.

Carter, R. A. A., \& Joll, C. A. (2017). Occurrence and formation of disinfection by-products in the swimming pool environment: A critical review. Journal of Environmental Sciences (China), 58, 19-50. https://doi.org/10.1016/j. jes.2017.06.013

Cavestri, R., \& Seeger-Clevenger, D. (2009). Chemical offgassing from indoor swimming pools. ASHRAE Transactions, 115, 502-512.

Chow, T. T., Bai, Y., Fong, K. F., \& Lin, Z. (2012). Analysis of a solar assisted heat pump system for indoor swimming pool water and space heating. [Article]. Applied Energy, 100, 309-317. https://doi.org/10.1016/j.apenergy.2012. 05.058

Chowdhury, S. (2016). DBPs in a chlorinated indoor swimming pool: occurrences and modeling. [Article]. Journal of Water Supply: Research and Technology - AQUA, 65(7), 550-563. https://doi.org/10.2166/aqua.2016.038

Chowdhury, S., Alhooshani, K., \& Karanfil, T. (2014). Disinfection byproducts in swimming pool: Occurrences, implications and future needs. Water Research, 53, 68-109. https://doi.org/10.1016/j.watres.2014.01.017

Chu, T. S., Cheng, S. F., Wang, G. S., \& Tsai, S. W. (2013). Occupational exposures of airborne trichloramine at indoor swimming pools in Taipei. [Article]. Science of the Total Environment, 461-462, 317-322. https://doi. org/10.1016/j.scitotenv.2013.05.012

Ciuman, P., \& Lipska, B. (2018). Experimental validation of the numerical model of air, heat and moisture flow in an indoor swimming pool. [Article]. Building and Environment, 145, 1-13. https://doi.org/10.1016/j.build env.2018.09.009

Dalton, J. (1802). Experimental essays on the constitution of mixed gases. Manchester Literary and Philosophical Society Memo, 5, 535-602.

Delgado Marín, J. P., Vera García, F., \& García Cascales, J. R. (2019). Use of a predictive control to improve the energy efficiency in indoor swimming pools using solar thermal energy. [Article]. Solar Energy, 179, 380-390. https://doi.org/10.1016/j.solener.2019.01.004

Duverge, J. J. (2019). Energy performance and water usage of aquatic centres. Dissertation. RMIT University.

Duverge, J. J., Rajagopalan, P., \& Fuller, R. (2017). Defining aquatic centres for energy and water benchmarking purposes. [Article]. Sustainable Cities and Society, 31, 51-61. https://doi.org/10.1016/j.scs.2017.02.008

Duverge, J. J., Rajagopalan, P., Fuller, R., \& Woo, J. (2018). Energy and water benchmarks for aquatic centres in Victoria, Australia. [Article]. Energy and Buildings, 177, 246-256. https://doi.org/10.1016/j.enbuild.2018. 07.043

Dyck, R., Sadiq, R., Rodriguez, M. J., Simard, S., \& Tardif, R. (2011). Trihalomethane exposures in indoor swimming pools: a level III fugacity model. [Article]. Water Research, 45(16), 5084-5098. https://doi.org/10.1016/j. watres.2011.07.005

Erdinger, L., Kuhn, K. P., Kirsch, F., Feldhues, R., Frobel, T., Nohynek, B., et al. (2004). Pathways of trihalomethane uptake in swimming pools. [Article]. International Journal of Hygiene and Environmental Health, 207(6), 571575. https://doi.org/10.1078/1438-4639-00329

EQUA Simulation AB. (2020). Building Performance - Simulation Software _ EQUA. https://www.equa.se. Accessed 15 Nov 2020.

European Commission. (2006). Directive 2006/32/EC of the European Parliament and of the Council of 5 April 2006 on energy end-use efficiency and energy services and repealing Council Directive 93/76. EEC.

European Commission (2019a). The European Green Deal.

European Commission. (2019b). Preparing the ground for raising long-term ambition - EU Climate Action Progress Report 2019.

European Union (2010). DIRECTIVE 2010/31/EU OF THE EUROPEAN PARLIAMENT AND OF THE COUNCIL of 19 May 2010 on the energy performance of buildings.

Fakour, H., \& Lo, S. L. (2018). Formation of trihalomethanes as disinfection byproducts in herbal spa pools. [Article]. Scientific Reports, 8(1), https://doi.org/10.1038/ s41598-018-23975-2.

Fernández-Luna, T., Burillo, P., Felipe, J. L., Gallardo, L., \& Tamaral, F. M. (2013). Chlorine concentrations in the air of indoor swimming pools and their effects on swimming pool workers. [Article]. Gaceta Sanitaria, 27(5), 411417. https://doi.org/10.1016/j.gaceta.2013.02.002

Font-Ribera, L., Kogevinas, M., Schmalz, C., Zwiener, C., Marco, E., Grimalt, J. O., et al. (2016). Environmental and personal determinants of the uptake of disinfection by-products during swimming. [Article]. Environmental Research, 149, 206-215. https://doi.org/10.1016/j.envres. 2016.05.013

Fuller, R., Rajagopalan, P., \& Duverge, J. J. (2017). Assessment and modelling of the viability of a solar heating system for aquatic centres in southern Australia. [Article]. Energy Efficiency, 10(5), 1269-1278. https://doi. org/10.1007/s12053-017-9517-4

Gabriel, M. F., Felgueiras, F., Mourão, Z., \& Fernandes, E. O. (2019). Assessment of the air quality in 20 public indoor swimming pools located in the Northern Region of Portugal. [Article]. Environment International, 133, https:// doi.org/10.1016/j.envint.2019.105274

Hang, C., Zhang, B., Gong, T., \& Xian, Q. (2016). Occurrence and health risk assessment of halogenated disinfection byproducts in indoor swimming pool water. [Article]. Science of the Total Environment, 543, 425-431. https:// doi.org/10.1016/j.scitotenv.2015.11.055

Hanssen., S. O., \& Mathisen., H. M. (1990). Evaporation from swimming pools Paper presented at the Roomvent, Oslo.

Hansen, K. M. S., Willach, S., Antoniou, M. G., Mosbæk, H., Albrechtsen, H. J., \& Andersen, H. R. (2012). Effect of $\mathrm{pH}$ on the formation of disinfection byproducts in swimming pool water - is less THM better? [Article]. Water Research, 46(19), 6399-6409. https://doi.org/10.1016/j. watres.2012.09.008

Harrington, C., \& Modera, M. (2013). Swimming pools as heat sinks for air conditioners: California feasibility analysis. [Article]. Energy and Buildings, 59, 252-264. https://doi. org/10.1016/j.enbuild.2012.12.038

Isaac, P. R. D., Hayes, C. R., \& Akers, R. K. (2010). Optimisation of water and energy use at the Wales National Pool. 
[Article]. Water and Environment Journal, 24(1), 39-48. https://doi.org/10.1111/j.1747-6593.2008.00150.x

JmaiffBlackstock, L. K., Wang, W., Vemula, S., Jaeger, B. T., \& Li, X. F. (2017). Sweetened swimming pools and hot tubs. Environmental Science and Technology Letters, 4(4), 149-153. https://doi.org/10.1021/acs.estlett.7b000 43

Johansson, L., \& Westerlund, L. (2001). Energy savings in indoor swimming-pools: Comparison between different heat-recovery systems. Applied Energy, 70(4), 281-303. https://doi.org/10.1016/S0306-2619(01)00043-5

Kampel, W. (2015). Energy efficiency in swimming facilities. $\mathrm{PhD}$ dissertation, Norwegian University of Science and Technology, Trondheim.

Kampel, W., Aas, B., \& Bruland, A. (2013). Energy-use in Norwegian swimming halls. Energy and Buildings, 59, 181-186. https://doi.org/10.1016/j.enbuild.2012.11.011

Kampel, W., Aas, B., \& Bruland, A. (2014). Characteristics of energy-efficient swimming facilities: A case study. Energy, 75, 508-512. https://doi.org/10.1016/j.energy. 2014.08.007

Kampel, W., Carlucci, S., Aas, B., \& Bruland, A. (2016). A proposal of energy performance indicators for a reliable benchmark of swimming facilities. Energy and Buildings, 129, 186-198. https://doi.org/10.1016/j.enbuild. 2016.07.033

Kic, P. (2016). Dust pollution in the sport facilities. Agronomy Research, 14(1), 75-81.

Kim, D., Ates, N., Kaplan Bekaroglu, S. S., Selbes, M., \& Karanfil, T. (2017). Impact of combining chlorine dioxide and chlorine on DBP formation in simulated indoor swimming pools. Journal of Environmental Sciences, 58, 155-162. https://doi.org/10.1016/j.jes.2017.04.020

Kim, H., Shim, J., \& Lee, S. (2002). Formation of disinfection by-products in chlorinated swimming pool water. Chemosphere, 46(1), 123-130. https://doi.org/10.1016/S00456535(00)00581-6

Kim, O., Knudsen, M. D., \& Petersen, S. (2018). Peak load reduction of district heating by control of indoor public swimming pool. In 2018 Building Performance Analysis Conference and SimBuild co-organized by ASHRAE and IBPSA-USA.

Klein, S., Beckman, W., Mitchell, J., Duffie, J., Duffie, N., Freeman, T., et al. (2017). TRNSYS 18. A TRaNsient SYstem Simulation Program; Standard Component Library 515 Overview. Solar Energy Laboratory, University of Wisconsin-Madison: Madison, WI, USA, 3, 516.

Köppen, W. P., \& Geiger, R. (1930). Handbuch der Klimatologie. Gebrüder Borntraeger.

Kuyumcu, M. E., Tutumlu, H., \& Yumrutaş, R. (2016). Performance of a swimming pool heating system by utilizing waste energy rejected from an ice rink with an energy storage tank. [Article]. Energy Conversion and Management, 121, 349-357. https://doi.org/10.1016/j.enconman. 2016.05.049

Lammers, J. T. H. (1978). Human factors, energy conservation and design practice. Eindhoven University of Technology.

Lebon, M., Fellouah, H., Galanis, N., Limane, A., \& Guerfala, N. (2017). Numerical analysis and field measurements of the airflow patterns and thermal comfort in an indoor swimming pool: a case study. Energy Efficiency, 10(3), 527-548. https://doi.org/10.1007/s12053-016-9469-0

Lévesque, B., Vézina, L., Gauvin, D., \& Leroux, P. (2015). Investigation of air quality problems in an indoor swimming pool: a case study. Annals of Occupational Hygiene, 59(8), 1085-1089. https://doi.org/10.1093/ annhyg/mev038

Li, Y., Nord, N., Huang, G., \& Li, X. (2020). Swimming pool heating technology: A state-of-the-art review. Building Simulation. https://doi.org/10.1007/s12273-020-0669-3

Li, Z., \& Heiselberg, P. K. (2005). CFD simulations for water evaporation and airflow movement in swimming baths. Instituttet for Bygningsteknik: Aalborg Universitet.

Limane, A., Fellouah, H., \& Galanis, N. (2017). Simulation of airflow with heat and mass transfer in an indoor swimming pool by OpenFOAM. International Journal of Heat and Mass Transfer, 109, 862-878. https://doi.org/10. 1016/j.ijheatmasstransfer.2017.02.030

Limane, A., Fellouah, H., \& Galanis, N. (2018). Three-dimensional OpenFOAM simulation to evaluate the thermal comfort of occupants, indoor air quality and heat losses inside an indoor swimming pool. Energy and Buildings, 167, 49-68. https://doi.org/10.1016/j.enbuild.2018.02. 037

Liu, L., Fu, L., \& Zhang, S. (2014). The design and analysis of two exhaust heat recovery systems for public shower facilities. [Article]. Applied Energy, 132, 267-275. https://doi.org/10.1016/j.apenergy.2014.07.013

Liviac, D., Wagner, E. D., Mitch, W. A., Altonji, M. J., \& Plewa, M. J. (2010). Genotoxicity of water concentrates from recreational pools after various disinfection methods. Environmental Science and Technology, 44(9), 3527-3532. https://doi.org/10.1021/es903593w

Lochner, G., \& Wasner, L. (2017). Ventilation requirements for indoor pools. ASHRAE Journal, 59, 16-18, 20, 22-24.

Lu, T., Lü, X., \& Viljanen, M. (2015). A new method for modeling energy performance in buildings. In J. Yan, T. Shamim, S. K. Chou, \& H. Li (Eds.), 7th International Conference on Applied Energy, ICAE 2015 (Vol. 75, pp. 1825-1831). Elsevier Ltd. https://doi.org/10.1016/j.egypro.2015.07.154

Luo, Z., Yang, S., Xie, N., Xie, W., Liu, J., Souley Agbodjan, Y., et al. (2019). Multi-objective capacity optimization of a distributed energy system considering economy, environment and energy. Energy Conversion and Management, 200, https://doi.org/10.1016/j.enconman.2019. 112081.

Manasfi, T., Coulomb, B., \& Boudenne, J. L. (2017). Occurrence, origin, and toxicity of disinfection byproducts in chlorinated swimming pools: An overview. International Journal of Hygiene and Environmental Health, 220(3), 591-603. https://doi.org/10.1016/j.ijheh.2017.01.005

Mancic', M. V., Zivkovic', D. S., Milosavljevic', P. M., \& Todorovic', M. N. (2014). Mathematical modelling and simulation of the thermal performance of a solar heated indoor swimming pool. Thermal Science, 18(3), 9991010. https://doi.org/10.2298/TSCI1403999M

Mančić, M. V., Živković, D. S., Djordjević, M. L., Jovanović, M. S., Rajić, M. N., \& Mitrović, D. M. (2018). Technoeconomic optimization of configuration and capacity of a polygeneration system for the energy demands of a 
public swimming pool building. Thermal Science, 22, S1535-S1549. https://doi.org/10.2298/TSCI18S5535M

Namini, S. B., Shakouri, M., Tahmasebi, M. M., \& Preece, C. (2014). Managerial sustainability assessment tool for Iran's buildings. Proceedings of the Institution of Civil Engineers - Engineering Sustainability, 167(1), 12-23. https://doi.org/10.1680/ensu.12.00041

Nitter, T. B., Carlucci, S., Olsen, S. N., \& Svendsen, K. V. H. (2019). Energy use and perceived health in indoor swimming pool facilities. In U. Berardi \& F. Allard (Eds.), 10th International Conference on Indoor Air Quality, Ventilation and Energy Conservation in Buildings, IAQVEC 2019 (4th ed., Vol. 609). Institute of Physics Publishing. https://doi.org/10.1088/1757-899X/609/4/ 042051

Nitter, T. B., Kampel, W., Svendsen, K. V. H., \& Aas, B. (2018). Comparison of trihalomethanes in the air of two indoor swimming pool facilities using different type of chlorination and different types of water. Water Science and Technology: Water Supply, 18(4), 1350-1356. https://doi.org/10.2166/ws.2017.201

Nitter, T. B., \& Svendsen, K. V. H. (2019a). Modelling the concentration of chloroform in the air of a Norwegian swimming pool facility - a repeated measures study. Science of the Total Environment, 664, 1039-1044. https://doi. org/10.1016/j.scitotenv.2019.02.113

Nitter, T. B., \& Svendsen, K. V. H. (2019). UV treatment and air quality in a pool facility. Water Science and Technology, 80(3), 499-506. https://doi.org/10.2166/wst.2019. 291

Norgesbyggforskningsinstitutt. (2003). 552.315 - Ventilasjon og avfuktning $i$ svømmehaller og rom med svфmmebasseng. Norges byggforskningsinstitutt.

Nouanegue, H. F., Sansregret, S., le Lostec, B., \& Daoud, A. (2011). Energy model validation of heated outdoor swimming pools in cold weather. In 12th Conference of International Building Performance Simulation Association Building Simulation 2011, BS 2011, Sydney, NSW, (pp. 2463-2468).

Parrat, J., Donzé, G., Iseli, C., Perret, D., Tomicic, C., \& Schenk, O. (2012). Assessment of occupational and public exposure to trichloramine in Swiss indoor swimming pools: a proposal for an occupational exposure limit. Annals of Occupational Hygiene, 56(3), 264-277. https://doi.org/10.1093/annhyg/mer125

Pietkun-Greber, I., \& Suszanowicz, D. (2018). The consequences of the inappropriate use of ventilation systems operating in indoor swimming pool conditions - analysis. In VI International Conference of Science and Technology INFRAEKO 2018 Modern Cities Infrastructure and Environment, 7-8 June 2018, France, (Vol. 45, pp. 00064 (00068 pp.), E3S Web Conf. (France)): EDP Sciences. https://doi.org/10.1051/e3sconf/20184500064.

Polak, K. (2008a). Ventøk 3.1.1 - Ventilasjon av svфmmehaller. https://www.kompetansebiblioteket.no/Ventok/Bruks omraade/3_1_1_Ventilasjon_av_svommehaller_I.aspx. Accessed 7 Aug 2020.

Polak, K. (2008b). Ventøk 3.1.2 - Ventilasjon av svømmehaller. https://www.kompetansebiblioteket.no/Ventok/Bruks omraade/3_1_2_Ventilasjon_av_svommehaller_II.aspx. Accessed 7 Aug 2020.
Poós, T., \& Varju, E. (2019). Review for prediction of evaporation rate at natural convection. Wärme-Und Stoffübertragung, 55(6), 1651-1660. https://doi.org/10.1007/ s00231-018-02535-4

Qiu, G. Q., \& Riffat, S. B. (2010). Experimental investigation on a novel air dehumidifier using liquid desiccant. International Journal of Green Energy, 7(2), 174-180. https:// doi.org/10.1080/15435071003673666

Rajagopalan, P. (2014). Energy performance of aquatic facilities in Victoria, Australia. Facilities, 32(9-10), 565-580. https://doi.org/10.1108/F-02-2013-0015

Rajagopalan, P., \& Jamei, E. (2015). Thermal comfort of multiple user groups in indoor aquatic centres. Energy and Buildings, 105, 129-138. https://doi.org/10.1016/j.enbui ld.2015.07.037

Rajagopalan, P., \& Luther, M. B. (2013). Thermal and ventilation performance of a naturally ventilated sports hall within an aquatic centre. Energy and Buildings, 58, 111122. https://doi.org/10.1016/j.enbuild.2012.11.022

Ratajczak, K., \& Piotrowska, A. (2019). Disinfection by-products in swimming pool water and possibilities of limiting their impact on health of swimmers. Geomatics and Environmental Engineering, 13(3), 71-92. https://doi. org/10.7494/geom.2019.13.3.71

Ratajczak, K., \& Szczechowiak, E. (2020). Energy consumption decreasing strategy for indoor swimming pools - decentralized ventilation system with a heat pump. Energy and Buildings, 206, 17. https://doi.org/10.1016/j. enbuild.2019.109574

Revel, G. M., \& Arnesano, M. (2014a). Measuring overall thermal comfort to balance energy use in sports facilities. Measurement: Journal of the International Measurement Confederation, 55, 382-393. https://doi.org/10.1016/j. measurement.2014.05.027

Revel, G. M., \& Arnesano, M. (2014b). Perception of the thermal environment in sports facilities through subjective approach. Building and Environment, 77, 12-19. https:// doi.org/10.1016/j.buildenv.2014.03.017

Ribeiro, E., Jorge, H. M., \& Quintela, D. A. (2011). HVAC system energy optimization in indoor swimming pools. In 2011 3rd International Youth Conference on Energetics, IYCE 2011, Leiria.

Ribeiro, E., Jorge, H. M., \& Quintela, D. A. (2016). An approach to optimised control of HVAC systems in indoor swimming pools. International Journal of Sustainable Energy, 35(4), 378-395. https://doi.org/10.1080/ 14786451.2014.907293

Richardson, S. D., DeMarini, D. M., Kogevinas, M., Fernandez, P., Marco, E., Lourencetti, C., et al. (2010). What's in the pool? A comprehensive identification of disinfection by-products and assessment of mutagenicity of chlorinated and brominated swimming pool water. Environmental Health Perspectives, 118(11), 1523-1530. https:// doi.org/10.1289/ehp.1001965

Riehmann, P., Hanfler, M., \& Froehlich, B. (2005). Interactive Sankey diagrams. Paper presented at the IEEE Symposium on Information Visualization, 2005. INFOVIS 2005.

Righi, E., Fantuzzi, G., Predieri, G., \& Aggazzotti, G. (2014). Bromate, chlorite, chlorate, haloacetic acids, and trihalomethanes occurrence in indoor swimming pool waters 
in Italy. Microchemical Journal, 113, 23-29. https://doi. org/10.1016/j.microc.2013.11.007

Rincon, L., Castell, A., Perez, G., Sole, C., Boer, D., \& Cabeza, L. F. (2013). Evaluation of the environmental impact of experimental buildings with different constructive systems using material flow analysis and life cycle assessment. Applied Energy, 109, 544-552. https://doi.org/10. 1016/j.apenergy.2013.02.038

Rojas, G., \& Grove-Smith, J. (2018). Improving ventilation efficiency for a highly energy efficient indoor swimming pool using CFD simulations. Fluids, 3(4), 10.3390/ fluids3040092.

Røkenes, H. (2011). Betraktninger rundt svømmehallers energieffektivitet. Master's thesis, Norwegian University of Science and Technology.

Ruiz, E., \& Martínez, P. J. (2010). Analysis of an open-air swimming pool solar heating system by using an experimentally validated TRNSYS model. Solar Energy, 84(1), 116-123. https://doi.org/10.1016/j.solener.2009.10.015

Ruparathna, R., Hewage, K., \& Sadiq, R. (2017). Developing a level of service (LOS) index for operational management of public buildings. Sustainable Cities and Society, 34, 159-173. https://doi.org/10.1016/j.scs.2017.06.015

Saleem, S., Dyck, R., Hu, G., Hewage, K., Rodriguez, M., \& Sadiq, R. (2019). Investigating the effects of design and management factors on DBPs levels in indoor aquatic centres. Science of the Total Environment, 651, 775-786. https://doi.org/10.1016/j.scitotenv.2018.09.172

Saunus, C. (2008). Swimming pools: planning - construction - operation; planning - construction - operation of private and public indoor and outdoor pools including whirlpools and therapeutic pools. Krammer.

Sedek, P., Brozda, J., \& Gazdowicz, J. (2008). Pitting corrosion of the stainless steel ventilation duct in a roofed swimming pool. Engineering Failure Analysis, 15(4), 281286. https://doi.org/10.1016/j.engfailanal.2007.03.006

Shah, M. M. (1992). Calculating evaporation from pools and tanks. (modified formula) (Evaporation). Heating, Piping, Air Conditioning, 64(4), 69.

Shah, M. M. (2002). Evaluation of available correlations for rate of evaporation from undisturbed water pools to quiet air. HVAC\&R Research, 8(1), 125. https://doi.org/10. 1080/10789669.2002.10391292

Shah, M. M. (2003). Prediction of evaporation from occupied indoor swimming pools. [Review]. Energy and Buildings, 35(7), 707-713. https://doi.org/10.1016/S03787788(02)00211-6

Shah, M. M. (2008). Analytical formulas for calculating water evaporation from pools. ASHRAE Transactions, 114(2), 610 .

Shah, M. M. (2012). Calculation of evaporation from indoor swimming pools: Further development of formulas. ASHRAE Transactions, 118(2), 460.

Shah, M. M. (2013). New correlation for prediction of evaporation from occupied swimming pools. (Report). ASHRAE Transactions, 119(2), 450.

Shah, M. M. (2014). Methods for calculation of evaporation from swimming pools and other water surfaces. (Report). ASHRAE Transactions, 120, 3-17.

Shaw, J. W. (1986). Indoor air quality of swimming pool enclosures. In Proceedings of the ASHRAE Conference IAQ
'86: Managing Indoor Air for Health and Energy Conservation., Atlanta, GA, USA (pp. 83-88), ASHRAE.

Skibinski, B., Uhlig, S., Müller, P., Slavik, I., \& Uhl, W. (2019). Impact of different combinations of water treatment processes on the concentration of disinfection byproducts and their precursors in swimming pool water. [Article]. Environmental Science and Technology, 53(14), 81158126. https://doi.org/10.1021/acs.est.9b00491

Smith, C. C., Jones, R. W., \& Lof, G. O. G. (1993). Energy requirements and potential savings for heated indoor swimming pools. Paper presented at the Proceedings of the 1993 Annual Meeting of the American Society of Heating, Refrigerating and Air-Conditioning Engineers, Inc.

Smith, C. C., Jones, R. W., \& Lof, G. O. G. (1994). Measurement and analysis of evaporation from an inactive outdoor swimming pool. Solar Energy, 53(1), 3-7. https:// doi.org/10.1016/S0038-092X(94)90597-5

Smith, C. C., Lof, G., Jones, R., Kittler, R., Jones, R. (1998) Rates of evaporation from swimming pools in active use/ discussion. 104, 514.

Song, C., Jing, W., Zeng, P., Yu, H., \& Rosenberg, C. (2018). Energy consumption analysis of residential swimming pools for peak load shaving. [Article]. Applied Energy, 220, 176-191. https://doi.org/10.1016/j.apenergy.2018. 03.094

Spiliotopoulou, A., Hansen, K. M. S., \& Andersen, H. R. (2015). Secondary formation of disinfection by-products by UV treatment of swimming pool water. [Article]. Science of the Total Environment, 520, 96-105. https://doi. org/10.1016/j.scitotenv.2015.03.044

Standard Norge. (2006). NS-EN ISO 7730-Ergonomics of the thermal environment.

Standard Norge (2012). NS 3701 - Criteria for passive houses and low energy buildings - Non-residential buildings.

Standard Norge (2019a). NS-EN 15288-1:2018 - Swimming pools for public use - Part 1: Safety requirements for design.

Standard Norge (2019b). NS-EN 16798-1 Energy performance of buildings - Ventilation for buildings - Part 1: Indoor environmental input parameters for design and assessment of energy performance of buildings addressing indoor air quality, thermal environment, lighting and acoustics (Module M1-6).

Stensaas, L. I. (1999). Ventilasjonsteknikk 1. Skarland Press AS.

Sun, P., Wu, J. Y., Wang, R. Z., \& Xu, Y. X. (2011). Analysis of indoor environmental conditions and heat pump energy supply systems in indoor swimming pools. Energy \& Buildings, 43(5), 1071-1080. https://doi.org/ 10.1016/j.enbuild.2010.08.004

Swim England (2016). The use of energy in swimming pools. https://www.swimming.org/library/documents/1187/ download. Accessed 23 July 2020.

Szala, M., \& Łukasik, D. (2018). Pitting corrosion of the resistance welding joints of stainless steel ventilation grille operated in swimming pool environment. [Article]. International Journal of Corrosion, 2018, https://doi.org/10. 1155/2018/9408670. 
Tegart, W. J., Sheldon, G. W., \& Griffiths, D. C. (1990). Climate change. The IPCC impacts assessment. Australian Government Pub. Service.

The Norwegian Ministry of Labour and Social Affairs (2011). Regulations concerning the design and layout of workplaces and work premises (the Workplace Regulations). https://www.lovdata.no/dokument/SFE/forskrift/201112-06-1356. Accessed 13 July 2020.

The Norwegian Ministry of Local Government and Modernisation (2017). Regulations on technical requirements for construction works (TEK17). https://www.lovdata.no/ dokument/LTI/forskrift/2017-06-19-840. Accessed 01 July 2020.

Trianti-Stourna, E., Spyropoulou, K., Theofylaktos, C., Droutsa, K., Balaras, C. A., Santamouris, M., et al. (1998). Energy conservation strategies for sports centers: Part B Swimming Pools. Energy and Buildings, 27(2), 123-135.

van Eck, N. J., \& Waltman, L. (2010). Software survey: VOSviewer, a computer program for bibliometric mapping. Scientometrics, 84(2), 523-538. https://doi.org/10. 1007/s11192-009-0146-3

Venkannah, S. Reducing fuel consumption and $\mathrm{CO} 2$ emission by properly selecting the parameters for pool heating. In 2002 IEEE AFRICON; 6th AFRICON Conference in Africa - Electrotechnological Services For Africa, George, 2002 (Vol. 2, pp. 571-578).

Verein Deutscher Ingenieure. (2010). VDI 2089 - Building services in swimming baths indoor pools. VEREIN DEUTSCHER INGENIEURE.

Viegas, C., Alves, C., Carolino, E., Rosado, L., \& Silva Santos, C. (2010). Prevalence of fungi in indoor air with reference to gymnasiums with swimming pools. [Article]. Indoor and Built Environment, 19(5), 555-561. https:// doi.org/10.1177/1420326X10380120

Weaver, W. A., Li, J., Wen, Y., Johnston, J., Blatchley, M. R., \& Blatchley, E. R., III. (2009). Volatile disinfection byproduct analysis from chlorinated indoor swimming pools. [Article]. Water Research, 43(13), 3308-3318. https://doi.org/10.1016/j.watres.2009.04.035

Weng, S., Li, J., \& Blatchley, E. R. (2012). Effects of UV254 irradiation on residual chlorine and DBPs in chlorination of model organic-N precursors in swimming pools. [Article]. Water Research, 46(8), 2674-2682. https://doi.org/ 10.1016/j.watres.2012.02.017
Weng, S. C., Li, J., Wood, K. V., Kenttämaa, H. I., Williams, P. E., Amundson, L. M., et al. (2013). UV-induced effects on chlorination of creatinine. [Article]. Water Research, 47(14), 4948-4956. https://doi.org/10.1016/j.watres. 2013.05.034

Westerlund, L., Dahl, J., \& Johansson, L. (1996). A theoretical investigation of the heat demand for public baths. Energy, 21(7), 731-737. https://doi.org/10.1016/03605442(96)00014-X

Woolley, J., Harrington, C., \& Modera, M. (2011). Swimming pools as heat sinks for air conditioners: model design and experimental validation for natural thermal behavior of the pool. [Article]. Building and Environment, 46(1), 187-195. https://doi.org/10.1016/j.buildenv.2010.07.014

World Health Organization. (2006). Guidelines for safe recreational water environments, Volume 2 Swimming pools and similar environments.

Xiao, F., Zhang, X., Zhai, H., Lo, I. M. C., Tipoe, G. L., Yang, M., et al. (2012). New halogenated disinfection byproducts in swimming pool water and their permeability across skin. [Article]. Environmental Science and Technology, 46(13), 7112-7119. https://doi.org/10.1021/ es3010656

Yuce, B., Haijiang, L., Rezgui, Y., Petri, I., Jayan, B., \& Chunfeng, Y. (2014). Utilizing artificial neural network to predict energy consumption and thermal comfort level: An indoor swimming pool case study. Energy and Buildings, 80, 45-56. https://doi.org/10.1016/j.enbuild.2014.04.052

Zemtsov, N., Hlava, J., Frantsuzova, G., Madsen, H., Junker, R. G., \& Jorgensen, J. B. (2017). Economic MPC based on LPV model for thermostatically controlled loads. In 2017 International Siberian Conference on Control and Communications, SIBCON 2017, Institute of Electrical and Electronics Engineers Inc. https://doi.org/10.1109/ SIBCON.2017.7998560.

Zhang, X., Yang, H., Wang, X., Zhao, Y., Wang, X., \& Xie, Y. (2015). Concentration levels of disinfection by-products in 14 swimming pools of China. [Article]. Frontiers of Environmental Science and Engineering, 9(6), 9951003. https://doi.org/10.1007/s11783-015-0797-7

Publisher's note Springer Nature remains neutral with regard to jurisdictional claims in published maps and institutional affiliations. 